\title{
Contract Design with Information Asymmetry in a Supply Chain under an Emissions Trading Mechanism
}

\author{
Xin $\mathrm{Ma}^{\mathrm{a}}{ }^{\mathrm{b}}$, William $\mathrm{Ho}^{\mathrm{b}}$, Ping $\mathrm{Ji}^{\mathrm{a}}$, Srinivas Talluri ${ }^{\mathrm{b}, \mathrm{c}^{*}}$ \\ ${ }^{\mathrm{a} D e p a r t m e n t ~ o f ~ I n d u s t r i a l ~ a n d ~ S y s t e m s ~ E n g i n e e r i n g, ~ T h e ~ H o n g ~ K o n g ~ P o l y t e c h n i c ~}$ \\ University, Hung Hom, Kowloon, Hong Kong \\ ${ }^{\mathrm{b}}$ Department of Management and Marketing, The University of Melbourne, 198 \\ Berkeley Street, Carlton, VIC 3010, Australia \\ ${ }^{c}$ Department of Supply Chain Management, Eli Broad College of Business, Michigan \\ State University, N370 Business Complex, East Lansing, MI 48824, United States \\ *Corresponding author; e-mail: talluri@,broad.msu.edu
}

\begin{abstract}
We aim to design an appropriate sourcing mechanism with information asymmetry in a supply chain with one manufacturer and multiple suppliers subject to an emissions trading scheme. The manufacturer purchases raw materials from suppliers, who hold private information regarding the green degree - i.e., the unit emission rates - of their raw materials. An appropriate strategy must be adopted by the manufacturer for the contract design, including a series of payments and the order quantities; the suppliers are subsequently invited to bid for the contracts. The basic model is formulated to assist the manufacturer in designing a reasonable contract for a single supplier. The characteristics of the optimal order quantity and payoff functions of
\end{abstract}


both the manufacturer and supplier are analyzed. A competitive procurement scenario with multiple suppliers is also discussed. With respect to the diversity of auctions, three different auction types are analyzed, including a green degree auction, a price auction with emissions targets, and a performance-based auction. In addition, an efficient emissions trading policy is established to guide manufacturers regarding how to balance their emission allowances based on the optimal order quantities. Our approach provides an effective decision support system for both the manufacturer and suppliers.

\section{Keywords}

Green procurement; Contract design; Emissions trading; Asymmetric information

\section{Introduction}

In confronting the challenges created by greenhouse gas (GHG) emissions and the market demand for sustainable products, firms are under strong pressure to minimize their impact on the environment. For example, green engineering has been proposed with two goals of reducing the generation of pollution at the source and minimizing the risk to human health and the environment (EPA 2014). Siemens AG has established its own sustainable goals. As a result, Siemens has built green factories to implement a green production cycle, i.e., one in which green materials are used in products to help preserve the environment (Rohrmus et al., 2013). In order to provide sustainable products, manufacturers have to purchase eco-friendly materials from 
suppliers. However, it is challenging for manufacturers sourcing sustainable materials as inputs (Agrawal and Lee, 2016), mainly because of the asymmetric green information of raw materials provided by suppliers.

In many cases, suppliers do not disclose complete details about their products, especially their core products, and may even conceal information about the environmental friendliness of materials used. The reason is straightforward, that is, suppliers will take a tremendous amount of time and capital to evaluate their carbon footprint (Pyper, 2013). The confidential green information can lead to the benefit loss for manufacturers. Genasci (2012) reported that non-governmental organizations (NGOs) in China investigated the supply chains of 49 brands, including Armani, Calvin Klein, Marks \& Spencer, Disney, Zara, and Polo Ralph Lauren, by requesting information about pollution management issues regarding the materials provided by their suppliers. These firms were identified as having contributed to environmental pollution because their suppliers concealed the green information (i.e., the release of emissions) regarding their products; eventually, the reputations and brand values of these firms were seriously affected by this scandal.

To improve the sustainability performance and to reduce climate risks of entire supply chains, firms have to work closely with their suppliers (HP, 2014). However, there exists a conflict between manufacturers and their suppliers. Manufacturers prefer to adopt sustainable raw materials, which can incur lower carbon emissions during the production processes. For example, Apple Inc. is switching to greener materials to create safer products and manufacturing processes. Using recycling 
materials can generate fewer carbon emissions such as aluminum than by mining and smelting new materials (Apple, 2016). For suppliers, the decision to offer environmental products to meet sustainability targets is costly, especially improving its production technologies. For example, as a textile and garment supplier, the Yeh Group has spent $\$ 3.5 \mathrm{~m}$ on each of its DyeCoo machines, and $\$ 10 \mathrm{~m}$ for equipment, research and development to produce sustainable DryDye clothing for Adidas, Peak Performance, Kjus, and Mizuno (Hepburn, 2015). Due to the enormous cost pressure, suppliers would not be willing to take risks to offer sustainable products. As a consequence, the GHG emissions which are incurred by suppliers to produce raw materials will be transferred to manufacturers during production processes. Here, we focus on the embodied carbon from transforming the raw materials into final products, known as the "cradle-to-gate". The embodied carbon not only involves carbon emissions to produce raw materials, but also includes other carbon emissions from the manufacturing processes to make final products (Circular Ecology, 2015).

In practice, different types of environmental regulations have been designed and implemented to curb global GHG emissions. An emissions trading scheme, as a market-based mechanism, has been successfully implemented in the United States of America and the European Union, especially for companies in carbon-incentive industries (Fahimnia et al., 2015; Zakeri et al., 2015). Constrained by carbon emissions regulations, a manufacturer needs to consider cooperating with suppliers who can provide lower prices and eco-friendly materials. According to the aforementioned cases, we see that the manufacturer cannot precisely know the carbon 
information of raw materials as this information is privately known to the supplier. Thus, the manufacturer must estimate the value of the embodied carbon information of raw materials to control its carbon emissions volumes and corresponding cost. It is challenging for a manufacturer to quantify the environmental costs and to choose environmental materials from upstream suppliers to reduce GHG emissions of their supply chain when facing asymmetric green information of raw materials. This motivates us to use contract design under emissions constraints with asymmetric green information to establish a mutually beneficial and efficient business model.

Researchers have studied the problem of carbon emissions regulations from the perspective of sustainable operations management (Hua et al. 2011; Choi, 2013; Jaber et al. 2013; Chen et al. 2013; Konur et al. 2014). Most of these studies focused on emissions control with classical operations research models, such as the economic order quantity (EOQ) and newsvendor models. However, researchers have paid less attention to the interaction between manufacturers and suppliers. This paper fills this gap by addressing the manner in which a manufacturer designs an appropriate procurement contract to maximize profits of both the manufacturer and suppliers through an effective mechanism, which is constrained by the emissions trading scheme. In addition, this paper studies a realistic contract design issue with asymmetric information.

Research questions addressed in this paper are as follows. First, how is an appropriate procurement contract designed for a manufacturer that is constrained by the emissions trading scheme? To balance the environmental costs, which are further 
determined by the carbon emissions volumes, the manufacturer must design appropriate contractual mechanisms to elicit suppliers' confidential information, i.e., the unit emission rates. In reality, decision makers have various preferences; that is, different evaluation criteria exist (e.g., the bidding price and the green degree), and different weights are associated with these criteria. Therefore, this paper focuses on the issue of contract design for a manufacturer with a single supplier by adopting different strategies, including the use of green degree auctions, price auctions with carbon emissions targets, and performance-based auctions.

Second, how is a contract for a competitive bidding scenario designed? Several researchers have primarily focused on the cooperative relationship between a retailer (or a manufacturer) and a supplier (Mukhopadhyay et al., 2009; Gan et al., 2010; Babich et al., 2012). Although a manufacturer often has to cooperate with multiple suppliers to satisfy its demand when facing economic globalization, the supplier with the lower green degree has the lower selling price, which can mean cost savings for the manufacturer. In addition, the manufacturer also needs to manage its emissions allowances through cooperation with different types of suppliers. Therefore, it is worth evaluating how an appropriate contract for a competitive bidding scenario with asymmetric information can be designed.

Third, how is the optimal order quantity under the emissions trading scheme determined? Emissions trading schemes not only affect the characteristics of the payoff function of the manufacturer but also influence its contract structure; the latter effect occurs because adoption of raw materials with various green degrees can incur 
different volumes of carbon emissions for the manufacturer. For example, to produce magnesium, using dolomite and magnesite can generate 5.13 and 2.83 tons of carbon emissions per ton of primary magnesium produced, respectively (IPCC, 2006). Trading with insufficient or redundant emission volumes can impact the profit of the manufacturer. Thus, the manufacturer needs to balance the procurement quantity and control its emission allowances.

The remainder of this paper is organized as follows. Section 2 presents the related literature. Section 3 introduces the basic context of the model. Section 4 describes and discusses the optimal contract structure and analyzes the characteristics of the optimal contract, the payoffs of both players, and the green degree of a supplier. Section 5 analyzes a general extension of the basic model with multiple independent suppliers. Section 6 studies the optimal emissions trading policy, the price auction with a carbon emissions target, and a performance-based auction. Section 7 illustrates the managerial implications of our research work. Section 8 concludes the paper and discusses future extensions. The Appendix provides all proofs.

\section{Literature Review}

This paper is related to two streams of literature, including the applications of carbon emissions regulations in procurement management, and supply chain contract design with asymmetric information.

\subsection{Carbon Emissions Regulations in Procurement Management}


To reduce global GHG emissions, a series of environmental regulations have been proposed and implemented all over the world. Several researchers have quantified these mechanisms from the procurement management aspect as shown in Table 1.

$<$ Insert Table 1 around here $>$

The first group of researchers applied the economic order quantity (EOQ) model. Hua et al. (2011) studied the single-product procurement issue with emissions trading, and examined the impacts of the carbon price and carbon cap on the order quantity. Their results show that the emissions trading mechanism was an effective way to help retailer reduce emissions, but increase the total cost. Wahab et al. (2011) determined the optimal production-shipment policy while considering the carbon emissions. The authors revealed that incorporating the environmental impact into the supply chain decisions reduces the frequency of shipments. Bouchery et al. (2012) developed a multi-objective EOQ model by integrating sustainability criteria into the classical EOQ model. The authors proved that the model can help decision makers to determine the effectiveness of different regulatory policies to control carbon emissions, and then identify the best option effectively. Chen et al. (2013) developed a carbon-constrained EOQ model to analyze the impact of emissions regulations, including carbon cap-and-offset, carbon caps, carbon taxes, and emissions trading, on the optimal order quantity. They provided conditions under which the emissions can be reduced significantly without significantly increasing cost.

The second group of researchers used the mixed integer linear programming model. Benjaafar et al. (2013) analyzed the effect of different emissions regulations 
on the procurement, production, and inventory management. The results indicated that firms could effectively reduce carbon emissions without significantly increasing costs by making only operational adjustments and by collaborating with other members of their supply chain. Jaber et al. (2013) studied the procurement and production optimization problems in a two-level supply chain in consideration of the different emissions trading schemes. The authors proved that the model can help decision makers to jointly minimize the inventory-related and carbon emissions costs of their supply chains when penalties for exceeding emissions limits are considered. Hammami et al. (2015) studied the impact of carbon tax and emissions cap schemes on procurement, production, and inventory decisions. The authors demonstrated that individual caps can achieve significant lower emissions but can paradoxically lead to increasing the per unit emissions.

The following researchers adopted the dynamic programming model. Gong and Zhou (2013) analyzed the impact of emissions trading on optimal production planning, where the manufacturer can use a more costly but cleaner green technology or a less costly but more polluting regular technology, or both, to carry out production. Their results show that the optimal technology selection is determined by the relationship between the additional cost per allowance saved and the trading prices. Ma et al. (2016) studied the impact of a carbon tax on calculating the optimal order quantity over the finite time horizon. An effective range for the carbon tax was established to assist the government in calculating an appropriate carbon tax for the manufacturing industry. 
Overall, there are two commonalities among the aforementioned articles. First, the environmental cost was considered as a fixed cost, and calculated passively. As the emissions information regarding the materials from suppliers is private to manufacturers, the quantification of environmental costs is difficult and the manufacturers have to calculate passively and indirectly. Second, the aforementioned articles only focus on the profit maximization of the manufacturers. However, the suppliers' perspective was not studied, and interaction behaviors between manufacturers and suppliers were neglected. To help the manufacturer reduce emissions, especially using sustainable materials, our paper quantifies the green degrees of materials from suppliers, which could provide an effective way to control GHG emissions from the sources of a supply chain. In addition, this paper develops a game model to study the interaction behaviors between the manufacturer and suppliers.

\subsection{Supply Chain Contract Design with Asymmetric Information}

Several researchers studied the supply chain contract design with asymmetric information as summarized in Table 2. First, most of the researchers considered asymmetric cost information in their supply chain contracting models (Corbett et al., 2004; Mukhopadhyay et al., 2009; Chaturvedi and Martínez-de-Albéniz, 2011; Özer and Raz, 2011; Çakanyıldırım et al., 2012; Fang et al., 2014; Li et al., 2015; Wagner 2015). Comparatively, the supply chain contract design with asymmetric demand information has attracted less attention (Cachon, 2003; Chen, 2007; Kalkanci and 
Erhun, 2012; Lee and Yang, 2013).

$<$ Insert Table 2 around here $>$

Second, with respect to the characteristics of asymmetric information, there are more researchers considering the binary opposite asymmetric information for both suppliers and manufacturers (Cachon, 2003; Özer and Raz, 2011; Çakanyıldırım et al., 2012; Lee and Yang, 2013; Fang et al., 2014; Li et al., 2015; Wagner 2015) than the continuous asymmetric information (Corbett et al., 2004; Chen, 2007; Mukhopadhyay et al., 2009; Chaturvedi Martínez-de-Albéniz, 2011; Kalkanci and Erhun, 2012).

Third, with respect to the number of players involved in the supply chain contracting model, there are two groups of studies. The majority of the studies focuses on one buyer/manufacturer-two/multiple suppliers (Chen, 2007; Chaturvedi and Martínez-de-Albéniz, 2011; Özer and Raz, 2011; Kalkanci and Erhun, 2012; Lee and Yang, 2013; Fang et al., 2014; Li et al., 2015). The other group of studies focuses on one buyer/manufacturer-one supplier (Cachon, 2003; Mukhopadhyay et al., 2009; Çakanyıldırım et al., 2012; Wagner 2015).

The study that is most similar to ours is that of Fang et al. (2014), in which the authors studied the supply-side competition with a newsvendor model. There are two major differences between Fang et al. (2014) and our model. First, Fang et al. (2014) assume that suppliers belong to two specific types or binary opposite. In our paper, the manufacturer can process the asymmetric information regarding the green degree of multiple suppliers and design attractive contract for suppliers. To achieve this goal, the private information of suppliers is extended as a continuous type in our model. 
Second, Fang et al. (2014) considered the asymmetric cost information, that is, the unit production cost of each supplier was privately informed. In our paper, we shed new light on the sustainable procurement decision in a supply chain, that is, we aim to study the impact of the asymmetric information about the green degrees of materials from suppliers on the supply chain contract design, as shown in Table 2.

The contributions of this paper can be summarized as follows. First, this paper is the first to study the constrained procurement decision issue for a manufacturer with asymmetric information about the green degrees of materials from a supplier under stochastic demand. In addition, different types of auctions, including price auctions with an emissions target and performance-based auctions, are designed to achieve a win-win situation for both the manufacturer and supplier. Second, besides studying the interaction behaviors between one manufacturer and one supplier, we extend the basic model to further study the case of multiple suppliers. Third, this study is also the first to analyze the impact of an emissions trading scheme on contract design in the presence of asymmetric information for the manufacturer. To overcome limited types of asymmetric information, the assumption about asymmetric information is extended as a continuous type. In addition, the effective emissions trading policy is derived based on the optimal procurement contract with asymmetric information to assist the manufacturer in balancing buying and selling emission allowances.

\section{Model Setup}




\subsection{Problem Description}

Due to the pressure of environmental regulations and market demand for sustainable products, a manufacturer or a leader of a supply chain has to make adjustments. For instance, HP collaborates with its production and non-production suppliers to reduce GHG emissions of their entire supply chain (HP, 2014). In this paper, we aim to assist a manufacturer in designing an attractive and efficient procurement contract sourcing sustainable materials from different types of suppliers such that the profits of both the manufacturer and its suppliers can be maximized. Herein, the green degree of materials is private and known only to a supplier, thus, the manufacturer needs to identify the private information during the decision making process. In order to comprehensively describe the aforementioned practical and complex issues, this paper will develop a mechanism design model with asymmetric information and multiple agents. The details of the model setting are described in the following section. The notation used in the model is summarized in Table 3.

$<$ Insert Table 3 around here $>$

\subsection{The Model}

This section considers a procurement issue in a supply chain with a manufacturer and $n(n \geq 1)$ potential suppliers to satisfy the random demand. To control the emission volumes from suppliers, the manufacturer needs to use and purchase environmentally friendly materials from suppliers. Assume that the demand of the manufacturer $(D)$ is a random variable. Its cumulative distribution function (cdf) is denoted by $\Phi(\cdot)$, and 
its probability density function (pdf) is denoted by $\phi(\cdot)$. Here, let $\theta_{i}$ denote the green degree of raw materials from supplier $i$. The green degree is also characterized by its type, which is known only by the supplier. Specifically, cooperation with a supplier of type $\theta_{i}$ directly impacts the emission volumes of the manufacturer.

However, the manufacturer only observes that the type of supplier has cdf $F(\theta)$ and pdf $f(\theta), \theta \in[\underline{\theta}, \bar{\theta}]$, where $\underline{\theta}<\bar{\theta}, F(\underline{\theta})=0$, and $F(\bar{\theta})=1$. Both the manufacturer and the suppliers are risk-neutral. The manufacturer aims at maximizing its expected profit by seeking an optimal procurement strategy. The different strategies are studied under two scenarios, procurement from a single supplier $(n=1)$ and competitive procurement among multiple suppliers $(n \geqslant 2)$.

Next, the scenario that focuses on procurement from a single potential supplier is studied. Regarding the cost structure of the manufacturer, the leftover product can be offered in the following period, and this generates salvage value. To reduce emission volumes, the manufacturer needs to design an appropriate menu of contracts, $(Q(\theta), M(Q(\theta)))$, for different types of suppliers. That is, if the supplier supplies a quantity $Q(\theta)$, then the supplier obtains revenue $M(Q(\theta))$ from the manufacturer. Under the emissions trading mechanism, the manufacturer first receives the initial emission allowances - that is, the manufacturer can emit a specified volume of emissions during the production process. Then, the manufacturer needs to make a decision to buy additional allowances from or sell redundant allowances to the trading market. Based on the brief analysis above, the objective functions of the manufacturer, $\Pi_{m}$, and the supplier, $\Pi_{s}$, can be formulated as follows. 


$$
\begin{aligned}
& \Pi_{m}=R(Q(\theta))+T(Q(\theta), C)-M(Q(\theta)), \\
& \Pi_{s}=M(Q(\theta))+\alpha \theta W(Q(\theta))-c_{s} Q(\theta),
\end{aligned}
$$

where

$$
\begin{aligned}
& R(Q(\theta))=p \mathrm{E} \min (D, Q(\theta))+r_{v} \mathrm{E}(Q(\theta)-D)^{+}-c_{p} Q(\theta), \\
& T(Q(\theta), C)=w_{1} \mathrm{E} \min (C-\beta Q(\theta))^{+}-w_{2} \mathrm{E} \min (\beta Q(\theta)-C)^{+} .
\end{aligned}
$$

Equation (1) describes the payoff function of the manufacturer. The first item in Equation (1), $R(Q(\theta))$, consists of the sales revenue, the salvage value of the leftover product, and the production cost. The details of $R(Q(\theta))$ are presented in Equation (3). The sales revenue equals the unit price times the expected quantity of sale. The salvage value is determined by the expected inventory level and the unit salvage revenue, $r_{v}$. The production cost equals the unit production cost $\left(c_{p}\right)$ multiplied by the order quantity, $Q(\theta)$. The second item in Equation (1), $T(Q(\theta), C)$, illustrates the expected revenue from emissions trading activity. The details of $T(Q(\theta), C)$ are presented in Equation (4). During the production processes, the unit emission factor of the manufacturer is denoted by the coefficient $\beta$. Thus, the total emissions amount of the manufacturer equals the product of $\beta$ and $Q(\theta)$, which is determined by the production technology of the manufacturer. Note that a linear function has been widely used to calculate the emissions of the production process (e.g., Krass et al., 2013). For a certain period, if the emission allowances $(C)$ of the manufacturer are greater than the total emissions amount, then the manufacturer could benefit from selling unneeded emission allowances; otherwise, the manufacturer should purchase the insufficient allowances from the carbon market. In Equation (4), $w_{2}$ and $w_{1}$ are 
the buying and selling prices of carbon emissions, respectively. Assume that $w_{1}$ is smaller than $w_{2}$, which is an incentive to encourage the manufacturer to accept and implement the emissions trading mechanism during the initial period (Gong and Zhou, 2013). Regarding the uncertainty of emission allowances of the manufacturer, we denote $H(\cdot)$ and $h(\cdot)$ as the cdf and pdf, respectively, of the allowance prices. The last item in Equation (1), $M(Q(\theta))$, is the cash transfer from the manufacturer to the supplier.

Equation (2) illustrates the payoff function of the supplier. The first item, $M(Q(\theta))$, is the cash transfer from the manufacturer. The second item, $\alpha \theta W(Q(\theta))$, describes the environmental benefits of the supplier, which equals the product of the coefficient $\alpha$, the green degree $\theta$, and the environmental quality function of the supplier $W(Q(\theta))$. The environmental benefits of the supplier can be explained as that of adopting a new technique or technology to produce raw materials. For instance, Apple Inc. implemented an innovative process to produce iPhone models that helps its suppliers, especially those in China, cut carbon emissions (Xinhua News, 2015). The most common practices of green supply chain management include assessing the environmental performance of suppliers to ensure the environmental quality of their products and evaluating the cost of waste in their operating systems (Handfield et al., 2002). Thus, in this paper, we denote the environmental quality function by $W(Q(\theta))$, which is the impact on the suppliers' type, $\theta$, without loss of generality, and $W(Q(\theta))$ is assumed to be an increasing concave function. The last item, $c_{s} Q(\theta)$, is the production cost of the materials, which is the multiplication of the unit production 
cost of the materials, $c_{s}$, and the order quantity, $Q(\theta)$.

For supplier participation, $\Pi_{s}$ should not be less than $\Pi_{0}$; this constraint is referred to as the individual rationality (IR) constraint. $\Pi_{0}$ is the tolerance of the supplier in accepting the contract. Without loss of generality, assume that $\Pi_{0}$ is zero. In addition, the incentive compatibility (IC) constraint must be satisfied as shown in equation (5). This constraint indicates that each supplier prefers to choose the contract that is designed for him. That is, if a supplier's type is $\theta$ and the contract designed for him is $(Q(\theta), M(Q(\theta)))$, then, the utility of the supplier choosing $Q(\theta)$ is larger than choosing any other contract, $\left(Q\left(\theta^{\prime}\right), M\left(Q\left(\theta^{\prime}\right)\right)\right)$.

$M(Q(\theta))+\alpha \theta W(Q(\theta))-c_{s} Q(\theta) \geq M\left(Q\left(\theta^{\prime}\right)\right)+\alpha \theta W\left(Q\left(\theta^{\prime}\right)\right)-c_{s} Q\left(\theta^{\prime}\right)$.

Therefore, the manufacturer's decision problem can be formulated as follows:

$$
\begin{aligned}
\max \Pi_{m}(\theta, Q(\theta)) & =\max \mathrm{E}[R(Q(\theta))+T(Q(\theta), C)-M(Q(\theta))] \\
& =\int_{\underline{\theta}}^{\bar{\theta}}[R(Q(\theta))+T(Q(\theta), C)-M(Q(\theta))] f(\theta) d \theta
\end{aligned}
$$

s.t. $M(Q(\theta))+\alpha \theta W(Q(\theta))-c_{s} Q(\theta) \geq \Pi_{0}=0$, for all $\theta$, $M(Q(\theta))+\alpha \theta W(Q(\theta))-c_{s} Q(\theta) \geq M\left(Q\left(\theta^{\prime}\right)\right)+\alpha \theta W\left(Q\left(\theta^{\prime}\right)\right)-c_{s} Q\left(\theta^{\prime}\right)$, for all $\theta$ and $\theta^{\prime}$.

In the following section, the properties of the manufacturer's decision issue in Equation (6) will be analyzed. The optimal contract will be derived. In addition, the relationship between the green degree of the supplier and the order quantity will be further discussed in the following sections.

\section{Contract Analysis and Implications}

To reduce GHG emissions during the production process, the manufacturer prefers to use sustainable materials. However, for suppliers, offering the environmental 
materials to meet sustainable requirements is costly. Therefore, there exists a conflict between a manufacturer and suppliers. Besides, the green degree of material is private and known only to a supplier. This private information can significantly affect the profitability, brand value, and reputation of the manufacturer as we discussed the brand scandal case (Genasci, 2012) in Section 1.

To study how an attractive and efficient procurement mechanism can be effectively designed under constraints of the asymmetric information (i.e., the green degree, $\theta$ ) and an emissions trading scheme, this section examines the properties of the manufacturer's decision problem specified by Equation (6). The technical approach applied here is a lattice and modularity analysis. The analysis presents propositions that illustrate the important properties of the manufacturer's payoff function, the optimal contact, and the supplier's profit. All proofs can be found in the Appendix.

The decision problem specified by Equation (6) assumes that the manufacturer does not have information regarding the supplier type, that is, the supplier does not offer its confidential information to the manufacturer. A supplier that does not disclose its confidential information can obtain a higher profit than the reservation profit (i.e., the profit of choosing nothing), but this type of behavior may lead to increases in the emission volume of the manufacturer. The information rent can be used appropriately to illustrate this phenomenon. The information rent is denoted as follows:

$$
r(\theta)=M(Q(\theta))+\alpha \theta W(Q(\theta))-c_{s} Q(\theta) .
$$


The first order derivative of the information rent $r^{\prime}(\theta)$ is $\alpha W(Q(\theta))$, which is greater than or equal zero. Thus, the information rent $r(\theta)$ must be an increasing function with respect to $\theta$, and $r(\underline{\theta})$ should equal zero; then, the $I R$ condition is automatically satisfied. On the basis of the above analysis, the objective function of the manufacturer can be re-written as follows:

$$
\begin{aligned}
\Pi_{m} & =\int_{\underline{\theta}}^{\bar{\theta}}[R(Q(\theta))+T(Q(\theta), C)-M(Q(\theta))] f(\theta) d \theta \\
& =\int_{\underline{\theta}}^{\bar{\theta}}\left[R(Q(\theta))+T(Q(\theta), C)-r(\theta)+\alpha \theta W(Q(\theta))-c_{s} Q(\theta)\right] f(\theta) d \theta
\end{aligned}
$$

Because the objective function of the manufacturer is decreasing in $r(\theta)$ and $r(\theta)$ is an increasing function, the information rent $r(\theta)$ and Equation (8) can be re-written as follows:

$$
\begin{aligned}
& r(\theta)=\int_{\underline{\theta}}^{\bar{\theta}} \alpha W(Q(\theta)) d \theta \\
& \Pi_{m}=\int_{\underline{\theta}}^{\bar{\theta}}\left[R(Q(\theta))+T(Q(\theta))-\alpha W(Q(\theta)) \frac{1-F(\theta)}{f(\theta)}+\alpha \theta W(Q(\theta))-c_{s} Q(\theta)\right] f(\theta) d \theta(10)
\end{aligned}
$$

Maximization of $\Pi_{m}$ corresponds to maximization of the integral function in Equation (10). Thus,

$$
\begin{aligned}
G(Q(\theta))= & R(Q(\theta))+T(Q(\theta))-\alpha W(Q(\theta)) \frac{1-F(\theta)}{f(\theta)}+\alpha \theta W(Q(\theta))-c_{s} Q(\theta) \\
= & p \mathrm{E} \min (Q(\theta), D)+r_{v} \mathrm{E}(Q(\theta)-D)^{+}-c_{p} Q(\theta)+w_{1} \mathrm{E}(C-\beta Q(\theta))^{+} \\
& -w_{2} \mathrm{E}(\beta Q(\theta)-C)^{+}-\alpha W(Q(\theta)) \frac{1-F(\theta)}{f(\theta)}+\alpha \theta W(Q(\theta))-c_{s} Q(\theta) .
\end{aligned}
$$

Proposition 1. The characteristics of $Q(\theta)$ and $G(Q(\theta))$ include the following:

(i) $Q(\theta)$ is an increasing function in $\theta$;

(ii) if $\theta \geq \frac{1-F(\theta)}{f(\theta)}, G(Q(\theta))$ is a concave function in $Q(\theta)$.

In Proposition 1, the first property describes the relationship between the order 
quantity and the green degree of the supplier. The increasing property demonstrates that the order quantity designed by the manufacturer is positively correlated with the green degree of the supplier. The first result is intuitive and consistent with real-world situations because the production emissions of the manufacturer are stable if there is no change to its production technology. The production quantity primarily determines the emission amount of the manufacturer for a certain period, which is also the main reason that the properties of the model focus on the interaction between the order quantity and the green degree. With respect to Equation (11), the second property in Proposition 1 illustrates the existence of the optimal order quantity, $Q(\theta)$, which can be assumed to be adopted. The results also indicate that the manufacturer can maximize its total profit by following the order quantity. Finally, the concavity of $G(Q(\theta))$ in $Q(\theta)$ indicates that the marginal value of the order quantity decreases if the order quantity increases.

Proposition 2. Given the condition of an increasing failure rate, $G(Q(\theta))$ is supermodular in $\theta, Q(\theta)$ and $w_{1}$ and is submodular in $Q(\theta)$ and $w_{2}$.

Based on the results described in Proposition 1, the monotonicity of $G(Q(\theta))$ is further discussed. The supermodularity of $G(Q(\theta))$ in $(\theta, Q(\theta))$ indicates that under the condition of an increasing failure rate, an increasing optimal match between the supplier type (the green degree of the supplier) and the optimal order quantity exists. For the manufacturer, the expected profit can be maximized by cooperating with the greener supplier; regarding the supplier, becoming greener results in increased competitive power because the supplier can claim a greater market share. In addition, 
the modularity of $G(Q(\theta))$ with respect to trading prices indicate that the manufacturer prefers to source greener materials if the selling price of emission allowances is increasing, that is, the manufacturer can make profit from emissions trading by selling its redundant emission allowances. Following the prosperities of $G(Q(\theta))$, the optimal menu of the contract for the supplier can be derived. The following proposition provides a detailed explanation.

Proposition 3. The characteristics of the optimal contract and the payoff function of the supplier include the following:

(i) Suppose that $\left(Q^{*}(\theta), M\left(Q^{*}(\theta)\right)\right)$ is the optimal menu of the contract, which is designed by the manufacturer. Then, the optimal payment for the supplier, $M\left(Q^{*}(\theta)\right)$, is

$$
M\left(Q^{*}(\theta)\right)=\int_{\underline{\theta}}^{\theta} \alpha W\left(Q^{*}(\xi)\right) d \xi+c_{s} Q^{*}(\theta)-\alpha \theta W\left(Q^{*}(\theta)\right)
$$

where $Q^{*}(\theta)=\operatorname{argmax} G(Q(\theta))$;

(ii) $\Pi_{s}$ is a supermodular function in $\theta$ and $Q(\theta)$.

The first property described in Proposition 3 describes the optimal contract, which depends on the green degree of the supplier. Following the optimal contract $\left(Q^{*}(\theta), M\left(Q^{*}(\theta)\right)\right)$, both the manufacturer and supplier can maximize their payoff functions simultaneously. Regarding the manufacturer, this optimal contract not only can assist them in controlling the emission amount from the source but also can develop a relatively stable relationship with the supplier under asymmetric information conditions. The supermodular nature of $\Pi_{s}$ in $(\theta, Q(\theta))$ indicates that the incremental revenue of the supplier in choosing a higher $Q(\theta)$ is greater when $\theta$ is 
higher. That is, a supplier can rapidly enlarge its business volume share by increasing its green degree.

Finally, contract design in the presence of multiple suppliers is worth studying. Facing multiple potential suppliers, the manufacturer should decide on the amount to purchase and which supplier(s) to cooperate with to maximize the expected payoff. These issues are further discussed in the following section.

\section{Decisions when Multiple Suppliers Are Available}

This section extends the basic model presented in Section 3 to the case of multiple suppliers. The first purpose is to check the robustness of the results presented in the previous section. Second, additional characteristics are analyzed in a general setting. Assume that a manufacturer has $n(n \geqslant 2)$ potential suppliers and each supplier is

characterized by their type, $\theta_{i}, \theta_{i} \in[\underline{\theta}, \bar{\theta}]$, which is confidential information known only by each individual supplier. The manufacturer and other suppliers have prior knowledge to characterize the supplier $i$ with $\operatorname{cdf} F_{i}\left(\theta_{i}\right)$ and pdf $f_{i}\left(\theta_{i}\right)$. The payoff functions of the manufacturer $\mathbb{I}_{m}^{0}$ and suppliers $\mathbb{I}_{s_{i}}$ can be formulated as follows:

$$
\begin{aligned}
& \underset{\mathrm{I} 0_{m}}{0_{m}}=\mathrm{E}\left[R\left(\sum_{i=1}^{n} Q_{i}\left(\theta_{1}, \mathrm{~K}, \theta_{n}\right)\right)+T\left(\sum_{i=1}^{n} Q_{i}\left(\theta_{1}, \mathrm{~K}, \theta_{n}\right)\right)-\sum_{i=1}^{n} M_{i}\left(Q_{i}\left(\theta_{1}, \mathrm{~K}, \theta_{n}\right)\right)\right], \\
& \mathrm{I}_{s_{i}}=m_{i}\left(q_{i}\left(\theta_{i}\right)\right)+\alpha_{i} \theta_{i} W\left(q_{i}\left(\theta_{i}\right)\right)-c_{s} q_{i}\left(\theta_{i}\right),
\end{aligned}
$$

where

$$
\begin{aligned}
R\left(\sum_{i=1}^{n} Q_{i}\left(\theta_{1}, \mathrm{~K}, \theta_{n}\right)\right)= & p \mathrm{E} \min \left(\sum_{i=1}^{n} Q_{i}\left(\theta_{1}, \mathrm{~K}, \theta_{n}\right), D\right) \\
& +r_{v} \mathrm{E}\left(\sum_{i=1}^{n} Q_{i}\left(\theta_{1}, \mathrm{~K}, \theta_{n}\right)-D\right)^{+}-c_{p} \sum_{i=1}^{n} Q_{i}\left(\theta_{1}, \mathrm{~K}, \theta_{n}\right)
\end{aligned}
$$




$$
T\left(\sum_{i=1}^{n} Q_{i}\left(\theta_{1}, \mathrm{~K}, \theta_{n}\right)\right)=w_{1} \mathrm{E}\left(C-\beta \sum_{i=1}^{n} Q_{i}\left(\theta_{1}, \mathrm{~K}, \theta_{n}\right)\right)^{+}-w_{2} \mathrm{E}\left(\beta \sum_{i=1}^{n} Q_{i}\left(\theta_{1}, \mathrm{~K}, \theta_{n}\right)-C\right)^{+}
$$

In the multiple-supplier scenario, Equation (14) consists of three items, the sales revenue, the salvage value of leftover products, and the production cost. The parameters in Equation (14) have same meaning as the parameters in Equation (3). Equation (15) describes the revenue or expenditure obtained by selling or purchasing the carbon emission allowances of the manufacturer. The emission volume of the manufacturer is determined by the total order quantity and the unit emission rate, $\beta$. The supplier $i$ payoff function in Equation (13) has the same meaning as in Equation (2). For an individual supplier $i$, the manufacturer only knows its type because $\theta_{i}$ is confidential information for the manufacturer. Thus, let $q_{i}\left(\theta_{i}\right)$ denote the manufacturer's preferred order quantity, which equals $\mathrm{E}_{\theta_{-i}} Q_{i}\left(\theta_{i}, \theta_{-i}\right)$; then, the payment is $\mathrm{E}_{i}\left(Q_{i}\left(\theta_{i}, \theta_{-i}\right)\right)$.

Let $\left(Q_{i}\left(\theta_{i}, \theta_{-i}\right), M_{i}\left(Q_{i}\left(\theta_{i}, \theta_{-i}\right)\right)\right)$ denote the contract structure, which is designed for individual suppliers, $i=1, \ldots, n$, where $\theta_{-i}$ represents the bids of all suppliers except for supplier $i . Q_{i}\left(\theta_{i}, \theta_{-i}\right)$ is the appropriate order quantity of supplier $i$ and $M_{i}\left(Q_{i}\left(\theta_{i}, \theta_{-i}\right)\right)$ is the payment transfer from the manufacturer to supplier $i$. Therefore, the manufacturer would announce a mechanism based on each supplier's bidding on the green degree. Each supplier can then make an individual decision as to whether to accept the contract. Each supplier aims to maximize its expected profit; thus, we assume that a supplier will accept the contract if and only if the expected profit is not less than zero. In addition, for supplier $i$ to choose the contract that is designed for it, the following $I C$ condition must hold: 
$m_{i}\left(q_{i}\left(\theta_{i}\right)\right)+\alpha_{i} \theta_{i} W\left(q_{i}\left(\theta_{i}\right)\right)-c_{s} q_{i}\left(\theta_{i}\right) \geq m_{i}\left(q_{i}\left(\theta_{i}\right)\right)+\alpha_{i} \delta W\left(q_{i}\left(\theta_{i}\right)\right)-c_{s_{i}} q_{i}\left(\theta_{i}\right)$

Therefore, the manufacturer's decision problem with multiple suppliers can be described as follows:

$$
\begin{aligned}
\mathrm{IO}_{m}= & \mathrm{E}\left[R\left(\sum_{i=1}^{n} Q_{i}\left(\theta_{1}, \mathrm{~K}, \theta_{n}\right)\right)+T\left(\sum_{i=1}^{n} Q_{i}\left(\theta_{1}, \mathrm{~K}, \theta_{n}\right)\right)-\sum_{i=1}^{n} M_{i}\left(Q_{i}\left(\theta_{1}, \mathrm{~K}, \theta_{n}\right)\right)\right] \\
\text { s.t. } & m_{i}\left(q_{i}\left(\theta_{i}\right)\right)+\alpha_{i} \theta_{i} W\left(q_{i}\left(\theta_{i}\right)\right)-c_{s} q_{i}\left(\theta_{i}\right) \geq 0, \\
& m_{i}\left(q_{i}\left(\theta_{i}\right)\right)+\alpha_{i} \theta_{i} W\left(q_{i}\left(\theta_{i}\right)\right)-c_{s} q_{i}\left(\theta_{i}\right) \geq m_{i}\left(q_{i}\left(\theta_{i}\right)\right)+\alpha_{i} \delta W\left(q_{i}\left(\theta_{i}\right)\right)-c_{s_{i}} q_{i}\left(\theta_{i}\right), \\
& \text { for all } \delta \text { and } \theta_{i} .
\end{aligned}
$$

We denote the information rent as $r_{i}\left(\theta_{i}\right)=m_{i}\left(q_{i}\left(\theta_{i}\right)\right)+\alpha_{i} \theta_{i} W\left(q_{i}\left(\theta_{i}\right)\right)-c_{s} q_{i}\left(\theta_{i}\right)$. The first order derivative of the information rent $r_{i}^{\prime}\left(\theta_{i}\right)$ is then $\alpha_{i} W_{i}\left(q_{i}\left(\theta_{i}\right)\right)$, which is greater than or equal zero. Thus, the information rent $r_{i}\left(\theta_{i}\right)$ must be increasing, and $r_{i}(\underline{\theta})$ should equal zero; consequently, the $I R$ condition is automatically satisfied. The expected payment from the manufacturer is given by Equation (18).

$$
\begin{aligned}
& \mathrm{E}\left[\sum_{i=1}^{n} M_{i}\left(Q_{i}\left(\theta_{1}, \mathrm{~K}, \theta_{n}\right)\right)\right]=\mathrm{E}\left[\sum_{i=1}^{n} m_{i}\left(q_{i}\left(\theta_{1}, \mathrm{~K}, \theta_{n}\right)\right)\right] \\
& =\sum_{i=1}^{n} \int_{\underline{\theta}}^{\bar{\theta}}\left[r_{i}\left(\theta_{i}\right)-\alpha_{i} \theta_{i} W_{i}\left(q_{i}\left(\theta_{i}\right)\right)+c_{s_{i}} q_{i}\left(\theta_{i}\right)\right] d F\left(\theta_{i}\right) \\
& =\int_{\underline{\theta}}^{\bar{\theta}} \mathrm{L} \int_{\underline{\theta}}^{\bar{\theta}}\left[c_{s_{i}} Q_{i}\left(\theta_{i}\right)-\alpha_{i} W_{i}\left(q_{i}\left(\theta_{i}\right)\right)\left(\theta_{i}-\frac{1-F_{i}\left(\theta_{i}\right)}{f_{i}\left(\theta_{i}\right)}\right)\right] d F\left(\theta_{i}\right),
\end{aligned}
$$

where $d F\left(\theta_{i}\right)=\prod_{i=1}^{n} d F_{i}\left(\theta_{i}\right)$.

Based on the above analysis, the objective function of the manufacturer can be re-written as follows: 


$$
\begin{aligned}
\mathrm{IY}_{m}= & \int_{\underline{\theta}}^{\bar{\theta}}\left[R\left(\sum_{i=1}^{n} Q_{i}\left(\theta_{1}, \mathrm{~K}, \theta_{n}\right)\right)+T\left(\sum_{i=1}^{n} Q_{i}\left(\theta_{1}, \mathrm{~K}, \theta_{n}\right)\right)-\sum_{i=1}^{n} M_{i}\left(Q_{i}\left(\theta_{1}, \mathrm{~K}, \theta_{n}\right)\right)\right] d F\left(\theta_{i}\right) \\
= & \int_{\underline{\theta}}^{\bar{\theta}}\left[R\left(\sum_{i=1}^{n} Q_{i}\left(\theta_{1}, \mathrm{~K}, \theta_{n}\right)\right)+T\left(\sum_{i=1}^{n} Q_{i}\left(\theta_{1}, \mathrm{~K}, \theta_{n}\right)\right)-r_{i}\left(\theta_{i}\right)+\alpha_{i} \theta_{i} W_{i}\left(q_{i}\left(\theta_{i}\right)\right)\right. \\
& \left.-c_{s_{i}} q_{i}\left(\theta_{i}\right)\right] d F\left(\theta_{i}\right) \\
= & \int_{\underline{\theta}}^{\bar{\theta}}\left[R\left(\sum_{i=1}^{n} Q_{i}\left(\theta_{1}, \mathrm{~K}, \theta_{n}\right)\right)+T\left(\sum_{i=1}^{n} Q_{i}\left(\theta_{1}, \mathrm{~K}, \theta_{n}\right)\right)-c_{s_{i}} Q_{i}\left(\theta_{i}\right)\right. \\
& \left.+\alpha_{i} W_{i}\left(q_{i}\left(\theta_{i}\right)\right)\left(\theta_{i}-\frac{1-F_{i}\left(\theta_{i}\right)}{f_{i}\left(\theta_{i}\right)}\right)\right] d F\left(\theta_{i}\right)
\end{aligned}
$$

Maximization of the manufacturer's payoff corresponds to maximization of the integrand function in Equation (19), which implies

$$
\begin{aligned}
K & \left(Q_{i}\left(\theta_{1}, \ldots, \theta_{n}\right)\right) \\
= & R\left(\sum_{i=1}^{n} Q_{i}\left(\theta_{1}, \ldots, \theta_{n}\right)\right)+T\left(\sum_{i=1}^{n} Q_{i}\left(\theta_{1}, \ldots, \theta_{n}\right)\right)-\sum_{i=1}^{n} M_{i}\left(Q_{i}\left(\theta_{1}, \ldots, \theta_{n}\right)\right) \\
= & p \mathrm{E} \min \left(\sum_{i=1}^{n} Q_{i}\left(\theta_{1}, \ldots, \theta_{n}\right), D\right)+r_{v} \mathrm{E}\left(\sum_{i=1}^{n} Q_{i}\left(\theta_{1}, \ldots, \theta_{n}\right)-D\right)^{+}-c_{p} \sum_{i=1}^{n} Q_{i}\left(\theta_{1}, \ldots, \theta_{n}\right) \\
& w_{1} \mathrm{E}\left(C-\beta \sum_{i=1}^{n} Q_{i}\left(\theta_{1}, \ldots, \theta_{n}\right)\right)^{+}-w_{2} \mathrm{E}\left(\beta \sum_{i=1}^{n} Q_{i}\left(\theta_{1}, \ldots, \theta_{n}\right)-C\right)^{+}-c_{s_{i}} Q_{i}\left(\theta_{i}\right) \\
& +\alpha_{i} W_{i}\left(Q_{i}\left(\theta_{i}\right)\right)\left(\theta_{i}-\frac{1-F_{i}\left(\theta_{i}\right)}{f_{i}\left(\theta_{i}\right)}\right)
\end{aligned}
$$

Proposition 4. For the scenario of multiple suppliers,

(i) $Q_{i}\left(\theta_{i}\right)$ is an increasing function in $\theta_{i}$;

(ii) if $\theta_{i} \geq \frac{1-F_{i}\left(\theta_{i}\right)}{f_{i}\left(\theta_{i}\right)}, K\left(Q_{i}\left(\theta_{1}, \mathrm{~K}, \theta_{n}\right)\right)$ is a concave function in $Q_{i}\left(\theta_{1}, \mathrm{~K}, \theta_{n}\right)$.

The first property of Proposition 4 presents the relationship between each individual type of supplier $i$ and each corresponding order quantity. The increasing characteristic indicates that suppliers can own a larger business volume share if they can supply raw materials with a higher green degree to the manufacturer. The emission amount for the manufacturer is determined by the type of supplier $i$. The second property of Proposition 4 illustrates the aspect of the integral function, 
$K\left(Q_{i}\left(\theta_{1}, \mathrm{~K}, \theta_{n}\right)\right)$, which directly determines the payoff function of the manufacturer. It implies that the marginal value from each supplier decreases if the order quantity increases. Therefore, the manufacturer should follow this rule to design the appropriate contracts.

Proposition 5. Under the condition of an increasing failure rate, $K\left(Q_{i}\left(\theta_{1}, \mathrm{~K}, \theta_{n}\right)\right)$ is a supermodular function in $\theta_{i}$ and $Q_{i}\left(\theta_{1}, \mathrm{~K}, \theta_{n}\right)$.

With respect to the monotonicity, Proposition 5 presents a characteristic of $K\left(Q_{i}\left(\theta_{1}, \mathrm{~K}, \theta_{n}\right)\right)$. The results indicate that the function $K\left(Q_{i}\left(\theta_{1}, \mathrm{~K}, \theta_{n}\right)\right)$ has increasing differences in $\theta_{i}$ and $Q_{i}\left(\theta_{1}, \mathrm{~K}, \theta_{n}\right)$. That is, the incremental gain in choosing a higher $Q_{i}\left(\theta_{1}, \mathrm{~K}, \theta_{n}\right)$ is greater if $\theta_{i}$ is greater. In a loose supplier market, a supplier with higher value of $\theta_{i}$ would build more market share. In addition, a higher order quantity brings more profit to the manufacturer. Therefore, the optimal results of the function $K\left(Q_{i}\left(\theta_{1}, \mathrm{~K}, \theta_{n}\right)\right)$ will be used to design the contract by the manufacturer. The details of the contract are provided in the following proposition.

Proposition 6. In a scenario with multiple suppliers,

(i) if $\theta_{1} \leq \theta_{2} \leq \mathrm{L} \leq \theta_{n}$, supplier $n$ is selected. $\left(Q^{*}\left(\theta_{n}\right), M_{n}\left(Q^{*}\left(\theta_{n}\right)\right)\right)$ is the optimal menu of the contract that is designed by the manufacturer, and the optimal payment for the supplier is

$$
M_{n}\left(Q_{n}^{*}\left(\theta_{n}\right)\right)=\int_{\underline{\theta}}^{\theta} \alpha_{n} W_{n}\left(Q_{n}^{*}(\xi)\right) d \xi+c_{s_{n}} Q_{n}^{*}\left(\theta_{n}\right)-\alpha_{n} \theta_{n} W_{n}\left(Q_{n}^{*}\left(\theta_{n}\right)\right),
$$

where $Q_{n}^{*}\left(\theta_{n}\right)=\arg \max K\left(Q_{i}\left(\theta_{1}, \mathrm{~K}, \theta_{n}\right)\right)$;

(ii) The payoff function of the selected supplier is supermodular in $\left(\theta_{n}, Q^{*}\left(\theta_{n}\right)\right)$.

In Proposition 6, the first result indicates that the optimal structure of a contract 
with a partially ordered set consists of the suppliers' types. With respect to the characteristics among $\theta_{i}, Q_{i}\left(\theta_{1}, \mathrm{~K}, \theta_{n}\right)$, and $K\left(Q_{i}\left(\theta_{1}, \mathrm{~K}, \theta_{n}\right)\right)$, the optimal purchasing contract is $Q^{*}\left(\theta_{1}, \mathrm{~K}, \theta_{n}\right)=Q^{*}\left(\theta_{n}\right)$ and $Q^{*}\left(\theta_{j}\right)=0, j=1,2, \mathrm{~K}, n-1 . Q^{*}\left(\theta_{n}\right)$ is the maximizer of the concave function $K\left(Q_{i}\left(\theta_{1}, \mathrm{~K}, \theta_{n}\right)\right)$. The second property of Proposition 6 implies that the suppliers' payoff is consistent with the manufacturer's payoff. This type of contract is a win-win situation in the pursuit of both parties' own interests. In addition, Propositions 4, 5, and 6 indicate that incentive schemes can also be applied to a scenario with $n$ independent potential suppliers.

This section discussed the extension of the basic model formulated in Section 3. Under a scenario with multiple independent suppliers, the robustness of the results were studied, and the results indicate that the scenario with multiple independent suppliers yield similar results as the optimal contract for a single supplier.

\section{Model Extensions}

\subsection{Emissions Trading Policy}

Based on the structured analysis of the payoff functions of suppliers and the manufacturer, this section focuses on studying the optimal emissions trading policy for the manufacturer. The details of the policy are as follows:

Proposition 7. Given an order quantity $Q(\theta)$, the optimal emissions trading policy is a piecewise function that is designed to maximize the payoff of the manufacturer. In addition, both the lower and the upper bounds increase in $Q(\theta)$. 


$$
C^{*}= \begin{cases}L(Q(\theta)), & \text { if } C \leq L(Q(\theta)) \\ C, & \text { if } L(Q(\theta)) \leq C \leq U(Q(\theta)), \\ U(Q(\theta)), & \text { if } C \geq L(Q(\theta))\end{cases}
$$

where

$$
\begin{aligned}
& U(Q(\theta))=\arg \max _{C}\left\{R(Q(\theta))-M(Q(\theta))+w_{1} \mathrm{E}(C-\beta Q(\theta))^{+}\right\} \\
& L(Q(\theta))=\arg \max _{C}\left\{R(Q(\theta))-M(Q(\theta))-w_{2} \mathrm{E}(\beta Q(\theta)-C)^{+}\right\} .
\end{aligned}
$$

Proposition 7 specifies the optimal emissions trading policy, which consists of the lower $(L(Q(\theta)))$ and upper $(U(Q(\theta)))$ bounds based on the emission allowances of the manufacturer. The emissions trading policy for the manufacturer can be summarized as follow. In a certain period, if the current emission allowances are greater than $U(Q(\theta))$, the manufacturer should sell the redundant emission volumes to the trading market; if the current emission allowances are less than $L(Q(\theta))$, the manufacturer should purchase additional allowances to cover the gap. That is, the manufacturer should increase its emission allowances to be at least $L(Q(\theta))$. Note that both the lower and upper bounds are non-decreasing in $Q(\theta)$. With the guidance of the emissions trading policy, the manufacturer can adjust its emission allowances in a timely manner to maximize its profit by holding appropriate emission allowances.

\subsection{Price Auction with a Carbon Emission Target}

Facing a carbon emission target, a manufacturer can calculate the required order quantity. That is, the manufacturer would select the target supplier with a fixed green degree and a reasonable price. We focus on the symmetric case, in which the confidential values of all suppliers are drawn from a common cdf $F$, which is a 
continuous function.

For the first price bid, suppose that all suppliers except supplier $i$ bid following function $\delta(\cdot)$; let $p$ denote the bidding price for supplier $i$. Assume that $\delta(\cdot)$ is an increasing function. The bidder wins if and only if $p<\delta^{-1}\left(p_{j}\right)$, or equivalently, $\delta^{-1}(p)<p_{j}$, for all $j \neq i$, which occurs with probability $\operatorname{Pr}\left(p_{j}>\delta^{-1}(p)\right)$. Here, we define that a function of the emission cost and the production cost for supplier $i$ is $\mu\left(\theta_{i}\right)$ times $p$. Therefore, supplier $i$ 's expected profit can be formulated as follows:

$\Pi_{i}=\left(x-\mu\left(\theta_{i}\right) p\right) \operatorname{Pr}\left(p_{j}>\delta^{-1}(p)\right)$

Proposition 8. Consider a price auction with an emission target. With $n$ independent suppliers, the symmetric Bayesian-Nash equilibrium bidding strategy on the first price bid is $\frac{\mathrm{E}(P \mid P \leq p)}{\mu\left(\theta_{i}\right)}$, where $P$ is the highest price among the remaining $n-1$ bidders, $P=\max \left\{p_{j}\right\}, j \neq i$. The second price bid for the weakly dominant strategy is $\frac{x}{\mu\left(\theta_{i}\right)}$.

In a price auction with a carbon emission target, the required order quantity is first determined by the emission capacity of the manufacturer. That is, the manufacturer establishes the target objectives for cooperation with a certain type of supplier. Thus, independent suppliers only aim at bidding on their profits. The advantages of this type of auction can further narrow the option pool for the manufacturer.

\subsection{A Performance-Based Auction}


In a performance-based auction, the supplier submits all of the bidding information simultaneously, including the green degree and the price. The manufacturer then evaluates the bidding information following the evaluation procedure. The evaluation results reflect the performance of suppliers from different dimensions. Without loss of generality, assume that a supplier submits $(\theta, M)$, which denotes the green degree and the cash transfer of a supplier, respectively. Let $V(\theta, M)$ denote the performance of a supplier, which is determined by the manufacturer. By adopting this auction type, the manufacturer cooperates with the supplier with the highest performance. The evaluation function for the determination of the suppliers' performance is as follows:

$V(\theta, p)=M(Q(\theta))+c_{m} Q(\theta)$

Proposition 9. For a performance-based auction,

(i) following the evaluation function, $V(\theta, M)$, the dominant strategy for a supplier is to bid the optimal green degree $\theta^{*}$ and $M^{*}$;

(ii) with $n$ independent suppliers, the symmetric equilibrium bidding strategy on the first bidding strategy is $\left(\theta^{*}\left(c_{s}\right), M^{*}\right)$, where $M^{*}=\delta\left(\theta^{*}\right)-c_{m} Q^{*}(\theta), \quad \delta\left(\theta^{*}\right)=\mathrm{E}\left[Z\left(\theta^{*}\right) \mid Y<v\right]$, $Y=\max \left\{v_{1}, v_{2}, \mathrm{~K}, v_{n-1}\right\}, Z\left(\theta^{*}\right)=\left(c_{s}+c_{m}\right) Q\left(\theta^{*}\right)-\alpha \theta^{*} W\left(Q\left(\theta^{*}\right)\right)$.

The intuition of Proposition 9 is straightforward: the optimal strategy for independent suppliers is to bid according to their green degree, which is essentially determined by the suppliers' production cost. Another parameter, the bidding price, is determined by the optimal value of the green degree $\theta^{*}$. This type of auction is an alternative method of selecting appropriate suppliers for the manufacturer. The difference between a price auction with an emission target and a performance-based 
auction is that the former only focuses on the price of the raw material from suppliers, whereas the latter provides a more comprehensive viewpoint for the manufacturer to design reasonable contracts. In addition, the evaluation function can also be modified to fit different decision preferences; that is, the performance function can be developed with other evaluation criteria.

\section{Managerial Implications}

Starting from the viewpoint of sustainable operations management, we presented a game model to illustrate the intersection of supplier evaluation, emissions trading mechanisms, and contract design with asymmetric information. The research results provide meaningful managerial implications for both the manufacturer and suppliers. The manufacturer can understand how to design attractive contracts to jointly maximize profit and emissions trading benefits. The suppliers can also have a better understanding of methods for maintaining or increasing their market shares and the mutual effects of the strategies on the manufacturer and suppliers. The suppliers can benefit from our findings by understanding the outcomes of adopting flexible strategies in different auction types.

In the following, we execute the game model with a numerical example to illustrate the analytical results and summarize the managerial implications for both the manufacturer and suppliers. We assume that the demand, $D$, the emission allowances, $C$, and the green degree, $\theta$, are uniformly distributed over the interval $(0,1)$. The $W(Q(\theta))$ function is assumed to be a linear case, $k Q(\theta)$. All the other parameters are 
given as follows, $p=40, w_{1}=20, w_{2}=30, c_{p}=15 ; c_{s}=20 ; \alpha=10, \beta=0.2, k=2, r_{v}=4.5, \theta \in$ $[0.1,1]$. Based on the analytical results, the optimal contract, $\left(Q^{*}(\theta), M\left(Q^{*}(\theta)\right)\right)$, and the optimal emissions trading thresholds are presented in Figures 1 and 2, respectively.

\author{
$<$ Insert Figure 1 around here $>$ \\ $<$ Insert Figure 2 around here $>$
}

For manufacturers, balancing the environmental cost and revenue is a key goal. In practice, the total emission volume of a manufacturer is predominantly determined by the green degree, $\theta$, of the raw materials from the suppliers. However, this factor is confidential information known only to the supplier. The results of the comparative statics indicate that $\theta$ brings a different concern to the manufacturer's decision and the payoffs of the manufacturer. Regarding the payoffs for the members of the supply chain, our research results indicate that the manufacturer prefers to offer a higher ordering quantity $Q(\theta)$ when $\theta$ is greater as shown in Figure 1. It is because the incremental revenue for the manufacturer is greater.

Based on the analytical results as shown in Figure 2, some managerial implications or guidelines for the manufacturer can be summarized as follows.

$>\quad$ The manufacturer needs to cooperate with a greener supplier with sufficient emission allowances because the manufacturer can spend less money to hold emission allowances.

$>$ The manufacturer can also select the supplier with a lower green degree and lower price if it has larger emission allowances. This reduces the procurement 
cost that can be used to purchase emission allowances from the carbon market.

To summarize, the effective emissions trading policy was established in this paper to guide the manufacturer in making reasonable trading decisions. As an example of a typical case in China, Beijing Eastern Petrochemical Co. Ltd. earned half a million RMB in profit from emissions trading in 2015 (BEP, 2015).

For suppliers, we first identified the optimal contract design between the manufacturer and a single supplier. The optimal contract not only can provide an effective control for the manufacturer but also can assist the manufacturer in developing a stable cooperative relationship in consideration of asymmetric information from suppliers. The results indicate that there are increasing differences in the payoffs of the suppliers with respect to the green degrees and supply quantities. To observe additional outcomes in a general setting, we further tested the robustness of the aforementioned results. In addition, two other types of auctions were analyzed for the supplier. Regarding a price auction with a carbon emissions target, the ordering quantity of the manufacturer is predominately determined by its emissions target, that is, a certain type of supplier is screened out. For a performance-based auction, the performance of suppliers is a key factor for the manufacturer in making procurement decisions. In such a scenario, the bidding information not only includes the green degree but also involves the price because these two factors operate simultaneously. The managerial implications or guidelines for suppliers are summarized as follows.

D A supplier can enlarge its market share by providing sustainable raw materials, 
which can be a strong competitive advantage for a supplier, as shown in Figure 1.

For a price auction with a carbon emission target, a supplier only aims at bidding by providing the most attractive price.

In a performance-based auction, a supplier has to bid by providing both attractive prices in consideration of its production cost and green degree simultaneously.

In general, to achieve the goal of mutual benefit of profit maximization and carbon emissions control, the aforementioned three types of mechanisms provide an effective method to promote sustainable operations for the upstream of a supply chain.

\section{Conclusions}

The issue of contract design in the presence of asymmetric information in a supply chain with a manufacturer and multiple suppliers facing uncertain demand and subject to an emissions trading scheme was studied in this work. According to the literature review in Section 2.1, several researchers studied the emissions control with perfect information using some classical operations research models to assist the manufacturer in making the optimal decision. However, the interaction behaviors between the manufacturer and suppliers are neglected. We shed new light on the sustainable procurement decision in a supply chain using a mechanism design model with asymmetric information (e.g., the green degree) to maximize the profits of both 
the manufacturer and suppliers and to reduce the GHG emissions for the manufacturer. Regarding the confidential information for the green degree of the raw materials of suppliers, the manufacturer needs to adopt effective procurement strategies to earn profit and control its emissions volumes under the emissions trading policy.

First, the basic model was developed. This model focuses on contract design with a single supplier. Following the emissions trading policy, the manufacturer seeks to maximize its profit by trading its emission allowances. The optimal procurement contract was derived with asymmetric information. The relationship between the green degree of a supplier and the optimal structure of the contract were further analyzed. Unlike the results of previous researches summarized in Section 2.1, the optimal contract is profitable for both the manufacturer and supplier with asymmetric information and emissions constraints.

Second, as shown in Table 2, the researchers either studied one manufacturer-one supplier or one manufacturer-multiple suppliers. In our paper, besides single supplier, the impact of multiple independent suppliers on the manufacturer's decisions was also studied. Based on the basic model, the second model was formulated for the general setting of multiple suppliers' competition. The robustness of the characteristics of a single supplier was analyzed.

Third, on the basis of a structured analysis of an auction with asymmetric information, an effective emissions trading policy for the manufacturer to control its carbon emission allowances was determined. The lower and upper bounds of the emission capacities for the manufacturer were derived to guide the manufacturer to 
balance its environmental costs effectively. In addition, two alternative auctions, including a price auction with an emission target and a green performance-based auction, were studied. These two auction types can provide flexible methods for a manufacturer to control its emissions.

In summary, this paper studied a novel and challenging procurement mechanism design issue for a manufacturer subjects to information asymmetry regarding its suppliers' green degrees. Our research outcomes provide insight into this procurement issue. Future research may investigate how the key factors, such as emissions trading prices and carbon taxes, affect the pricing issue for the manufacturer. In addition, it is worthwhile to study methods of selecting the appropriate factory locations for the manufacturers under different types of carbon emissions regulations. 


\section{References}

Agrawal V., Lee D., 2016. The effect of sourcing policies on a supplier's sustainable practices. Working paper.

Apple, 2016. Environmental responsibility report. http://www.apple.com/environment

Babich V., Li H., Ritchken P., Wang Y., 2012. Contracting with asymmetric demand information in supply chains. European Journal of Operational Research, 217(2): $333-341$.

Benjaafar S., Li Y., Daskin M., 2013. Carbon footprint and the management of supply chains: insights from simple models. IEEE Transaction on Automatic Science. Engineering, 10: 99-116.

Beijing Eastern Petrochemical Co.Ltd., 2016. http://www.dfpc.com.cn/News.aspx

Bouchery Y., Ghaffari A., Jemai A., Dallery Y., 2012. Including sustainability criteria into inventory models. European Journal of Operational Research, 222(2): 229-240.

Cachon, G., 2003. Supply chain coordination with contracts, in The Handbook of Operations Research and Management Science: Supply Chain Management, Graves, S. and De Kok, T. (eds), Elsevier, Amsterdam, The Netherlands.

Chaturvedi A., Martínez-de-Albéniz V., 2011. Optimal procurement design in the presence of supply risk. Manufacturing \& Service Operations Management, 13(2): $227-243$.

Chen F., 2007. Auctioning supply contracts. Management Science, 53(10): $1562-1576$.

Chen X., Benjaafara S., Elomri A., 2013. The carbon-constrained EOQ. Operations Research Letters, 41(2): 172-179.

Choi T.M., 2013. Optimal apparel supplier selection with forecast updates under carbon emission taxation scheme. Computers \& Operations Research, 40(11): 2646-2655.

Circular Ecology, 2015. Embodied carbon assessment. http://www.circularecology.co m/embodied-carbon.html

Corbett C.J., Zhou D., Tang C.S., 2004. Designing supply contracts: Contract type 
and information asymmetry. Management Science, 50(4): 550-559.

Çakanyıldırım M., Feng Q., Gan X., Sethi S.P., 2012. Contracting and coordination under asymmetric production cost information. Production and Operations Management, 21(2): 345-360.

Fahimnia B., Sarkis J., Choudhary A., Eshragh A., 2015. Tactical supply chain planning under a carbon tax policy scheme: A case study. International Journal of Production Economics, 164: 206-215.

Fang X., Ru J., Wang Y.Z., 2014. Optimal procurement design of an assembly supply chain with information asymmetry. Production and Operations Management, 23(12): 2075-2088.

Gan X., Srthi S.P., Zhou J., 2010. Commitment-penalty contracts in drop-shipping supply chains with asymmetric demand information. European Journal of Operational Research, 204(3): 449-462.

Genasci L., 2012. China NGOs tell brands to stop green washing. China Water Risk. http://chinawaterrisk.org/resources/analysis-reviews/chin-ngos-tell-brands-to-st op-greenwashing/

Gong X., Zhou X., 2013. Optimal production planning with emissions trading. Operations Research, 61(4): 908-924.

Hammami R., Nouira I., Frein Y., 2015. Carbon emissions in a multi-echelon production-inventory model with lead time constraints. International Journal of Production Economics, 164: 292-307.

Handfield R.B., Nichols E.L., 2002. Supply Chain Redesign: Transforming Supply Chains into Integrated Value Systems. FT Press.

Hepburn S., 2015. Nike and Adidas show cautious support for eco-friendly dye technology.

https://www.theguardian.com/sustainable-business/sustainable-fashio

n-blog/2015/apr/24/nike-and-adidas-show-cautious-support-for-eco-friendly-dy e-technology

HP, 2014. Living progress report. http://h20195.www2.hp.com/V2/GetPDF.aspx/c041 52740.pdf 
Hua G., Cheng T.C.E., Wang S., 2011. Managing carbon footprints in inventory management. International Journal of Production Economics, 132(2): 178-185.

IPCC, 2006. http://www.ipcc-nggip.iges.or.jp/public/2006gl/pdf/3_Volume3/V3_4_C h4_Metal_Industry.pdf

Jaber M.Y., Glockb C.H., Saadany Ahmed M.A. El., 2013. Supply chain coordination with emissions reduction incentives. International Journal of Production Research, 51(1): 69-82.

Kalkanci, B. and Erhun, F., 2012. Pricing games and impact of private demand information in decentralized assembly systems. Operations Research, 60(5): $1142-1156$.

Konur D., Schaefer B., 2014. Integrated inventory control and transportation decisions under carbon emissions regulations: LTL vs. TL carriers. Transportation Research Part E, 68: 14-38.

Krass D., Nedorezov T., Ovchinnikov A., 2013. Environmental Taxes and the Choice of Green Technology. Production and Operations Management, 22(5): 1035-1055.

Lee C.Y., Yang R., 2013. Supply chain contracting with competing suppliers under asymmetric information. IIE Transactions, 45(1): 25-52.

Li Z., Shao L. Sun D., 2015. Designing multi-attribute procurement mechanisms for assortment planning. Decision Sciences, 46(3):597-622.

Ma X., Ji P., Ho W., Yang C., 2016. Optimal procurement decision with a carbon tax for the manufacturing industry. Computers \& Operations Research. (in press)

Mukhopadhyay S.K., Su X., Ghose S., 2009. Motivating retail marketing effort: Optimal contract design. Production and Operations Management, 18(2): 197-211.

Özer Ö., Raz G., 2011. Supply chain sourcing under asymmetric information. Production and Operations Management, 2011, 20(1): 92-115.

Pyper J., 2013. Suppliers follow Wal-Mart's lead to reduce carbon emissions. http://mi dwestenergynews.com/2013/05/23/suppliers-follow-wal-marts-lead-to-reduce-c 
arbon-emissions/

Rohrmus D., Döricht V., and Weinert N., 2013. Green Cycles Economy and Factory. Re-engineering Manufacturing for Sustainability, 577-582.

United States Environmental Protection Agency (EPA). 2014. Green Engineering. http://www.epa.gov/oppt/greenengineering/

Wahab M.I.M., Hamun S.M.H., Ongkunaruk P., 2011. EOQ models for a coordinated two-level international supply chain considering imperfect items and environmental impact. International Journal of Production Economics, 134: 151-158.

Wagner M.R., 2015. Robust purchasing and information asymmetry in supply chains with a price-only contract. IIE Transactions, 47(8): 819-840.

Xinhua News. 2015. Apple's suppliers in China benefit from environmental innovation. http://news.xinhuanet.com/english/2015-09/22/c\$\\$134646108.htm

Zakeri A., Dehghanian F., Fahimnia B., Sarkis J., 2015. Carbon pricing versus emissions trading: A supply chain planning perspective. International Journal of Production Economics, 164: 197-205. 
Table 1. Carbon emissions regulations in procurement management

\begin{tabular}{|l|l|l|}
\hline Authors & Specific problems & Approaches \\
\hline Hua et al. (2011) & $\begin{array}{l}\text { A single-product procurement issue with } \\
\text { emissions trading }\end{array}$ & EOQ model \\
\hline Wahab et al. (2011) & $\begin{array}{l}\text { The optimal production-shipment policy with } \\
\text { carbon emissions }\end{array}$ & EOQ model \\
\hline Bouchery et al. (2012) & Inventory and emissions control & Multi-objective EOQ model \\
\hline Benjaafar et al. (2013) & $\begin{array}{l}\text { Coordination of procurement, production, and } \\
\text { inventory with emissions regulations }\end{array}$ & Mixed integer linear programing model \\
\hline Chen et al. (2013) & $\begin{array}{l}\text { The optimal order quantity with emissions } \\
\text { regulations }\end{array}$ & EOQ model \\
\hline Gong and Zhou (2013) & $\begin{array}{l}\text { The optimal production and inventory } \\
\text { planning with carbon emissions trading }\end{array}$ & Dynamic programming model \\
\hline Jaber et al. (2013) & $\begin{array}{l}\text { Coordination of procurement and production } \\
\text { with emissions trading schemes }\end{array}$ & Mixed integer linear programing model \\
\hline Hammami et al. (2015) & $\begin{array}{l}\text { Coordination of procurement, production, and } \\
\text { inventory with carbon tax and emissions cap }\end{array}$ & Mixed integer linear programing model \\
\hline Ma et al. (2016) & The optimal order quantity with carbon tax & Dynamic programming model \\
\hline
\end{tabular}

Table 2. Supply chain contract design with asymmetric information

\begin{tabular}{|c|c|c|c|}
\hline Authors & $\begin{array}{l}\text { Asymmetric } \\
\text { information }\end{array}$ & $\begin{array}{l}\text { Information } \\
\text { characteristics }\end{array}$ & Players in the game \\
\hline Cachon (2003) & Demand & Binary opposite & One manufacturer-one supplier \\
\hline Corbett et al. (2004) & Production costs & Continuous & Two buyers-one supplier \\
\hline Chen (2007) & Production costs & Continuous & One manufacturer-multiple suppliers \\
\hline Mukhopadhyay et al. (2009) & The cost of effort & Continuous & One manufacturer-one sales agent \\
\hline Chaturvedi Martínez-de-Albéniz (2011) & Production costs & Continuous & One buyer-multiple suppliers \\
\hline Özer and Raz (2011) & Production costs & Binary opposite & One manufacturer-two suppliers \\
\hline Çakanyıldırım et al. (2012) & Production costs & Binary opposite & One retailer-one supplier \\
\hline Kalkanci and Erhun (2012) & Demand & Continuous & One manufacturer-two suppliers \\
\hline Lee and Yang (2013) & Demand & Binary opposite & One retailer-two suppliers \\
\hline Fang et al. (2014) & Production costs & Binary opposite & One assembler-multiple suppliers \\
\hline Li et al. (2015) & Production costs & Binary opposite & One manufacturer-two suppliers \\
\hline Wagner (2015) & Production costs & Binary opposite & One retailer-one supplier \\
\hline Our paper & $\begin{array}{l}\text { The green degrees of } \\
\text { materials }\end{array}$ & Continuous & $\begin{array}{l}\text { One manufacturer-one supplier; } \\
\text { One manufacturer-multiple suppliers }\end{array}$ \\
\hline
\end{tabular}


Table 3. Notation

\begin{tabular}{|l|l|}
\hline$n$ & the number of suppliers, $n \geq 1$ \\
\hline$D$ & the demand of the manufacturer \\
\hline$\Phi()$ & the cumulative distribution function (cdf) of the demand \\
\hline$\phi()$ & the probability density function (pdf) of the demand \\
\hline$F$ & the green degree of the raw materials from a supplier \\
\hline$f(\theta)$ & the cdf of $\theta$ \\
\hline$Q(\theta)$ & the pdf of $\theta$ \\
\hline$M(Q(\theta))$ & the order quantity offered to a supplier with the green degree of $\theta$ \\
\hline$\Pi_{m}$ & the revenue from the manufacturer \\
\hline$\Pi_{s}$ & the payoff function of the manufacturer \\
\hline$R(Q(\theta))$ & the payoff function of the supplier \\
\hline$p$ & the sales revenue of the manufacturer \\
\hline$r_{v}$ & the unit price \\
\hline$c_{p}$ & the unit salvage revenue \\
\hline$C$ & the unit production cost \\
\hline$T(Q(\theta), C)$ & the emission allowances of the manufacturer \\
\hline$w_{1}$ & the expected revenue from emissions trading \\
\hline$w_{2}$ & the buying prices of carbon emissions \\
\hline$\beta$ & the unit emission factor of the manufacturer \\
\hline$H()$ & the cdf of the emission allowances of the manufacturer \\
\hline$h()$ & the pdf of the emission allowances of the manufacturer \\
\hline$W(Q(\theta))$ & the environmental quality function \\
\hline$c_{s}$ & the unit production cost of the materials \\
\hline
\end{tabular}




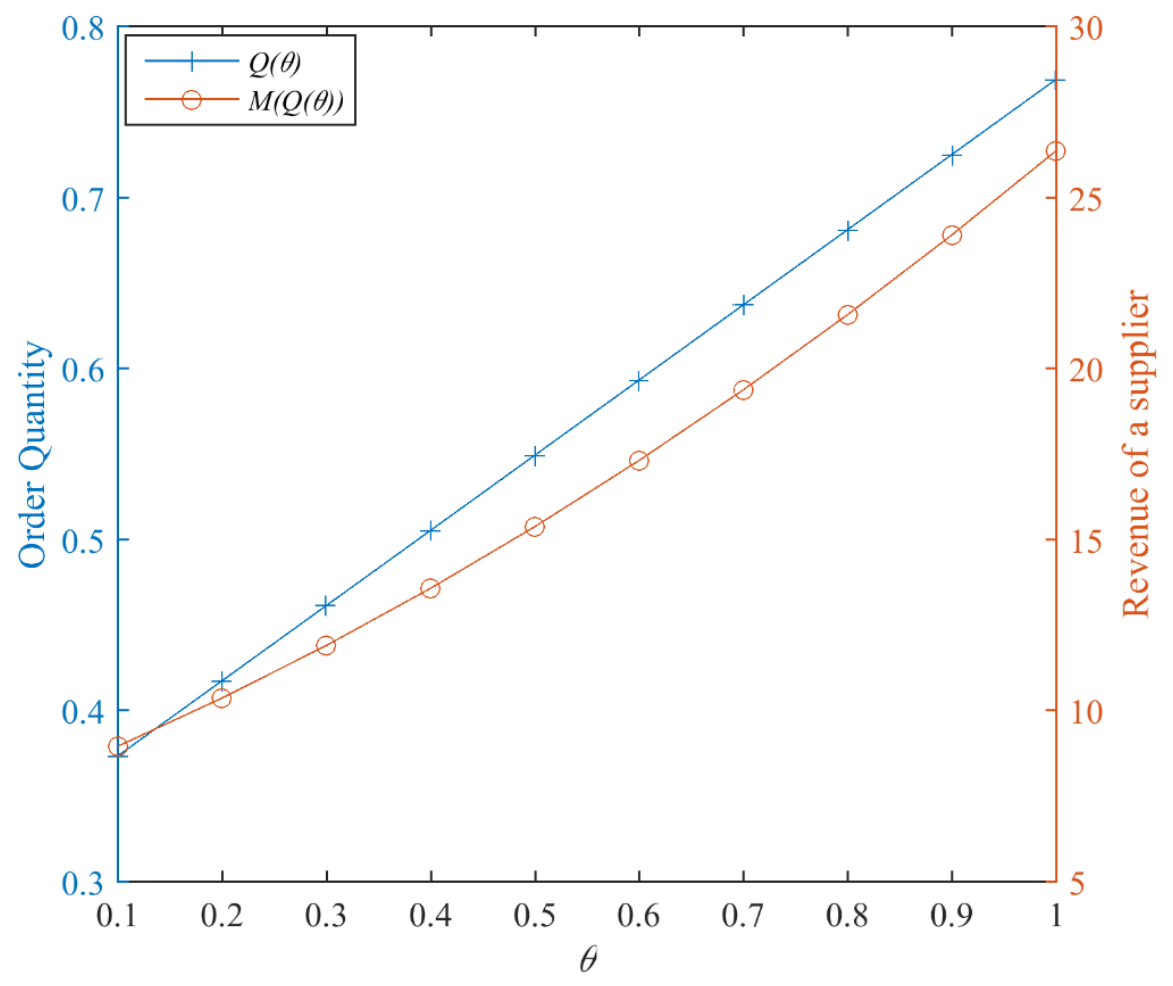

Figure 1. The relationship between the optimal contract and the green degree

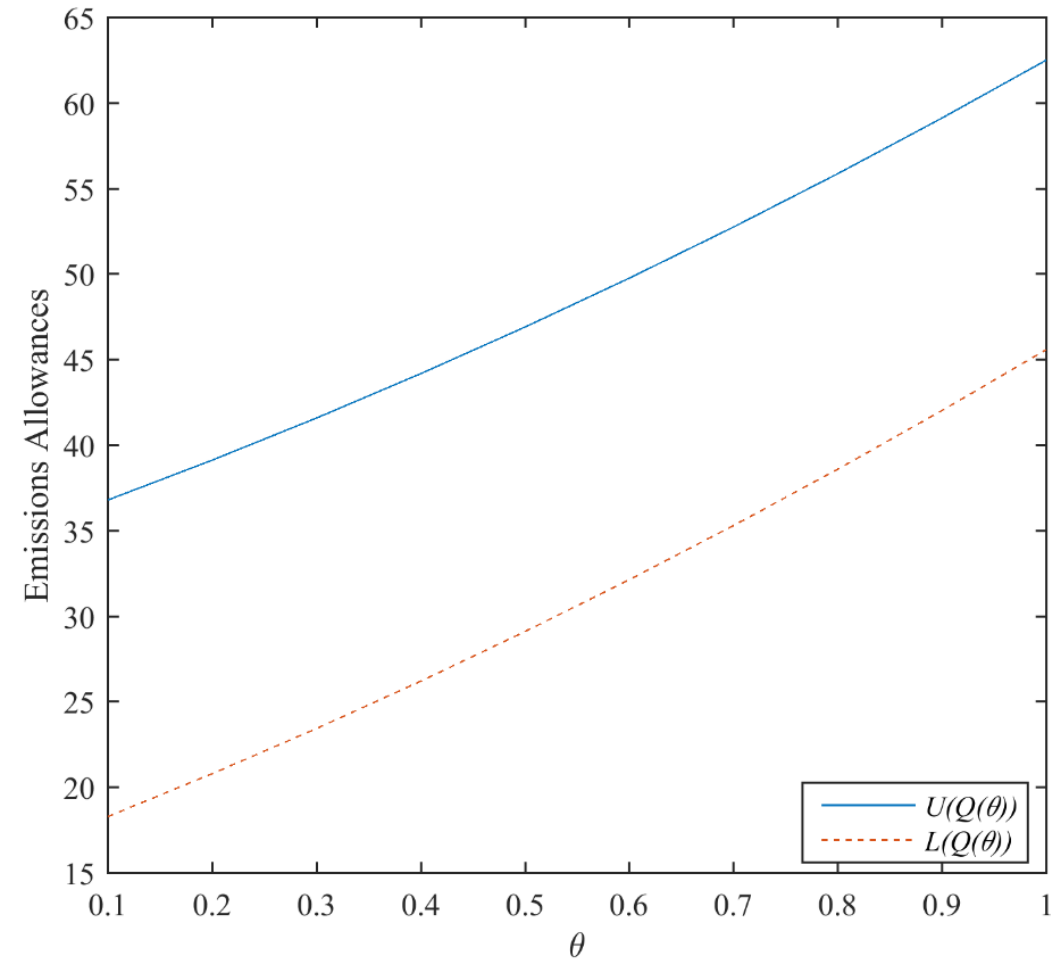

Figure 2. The optimal emissions trading thresholds for the manufacturer 


\section{APPENDICES}

\section{PROOF OF PROPOSITION 1.}

(i) Based on the $I C$ condition in Equation (5), the payoff function of the supplier $\Pi_{s}$ can be maximized when $\theta^{\prime}$ equals $\theta$, that is, the result of the first order derivative of the right hand-side of Equation (5) for $\theta^{\prime}$ equals zero when $\theta^{\prime}=\theta$, i.e.,

$$
\left[M^{\prime}(Q(\theta))+\alpha \theta W^{\prime}(Q(\theta))-c_{s}\right] Q^{\prime}(\theta)=0 \text {. }
$$

For further analysis of the characteristics of $Q(\theta)$, the second order derivative for $\theta$ is shown as follows:

$$
\begin{aligned}
& M^{\prime \prime}(Q(\theta))\left[Q^{\prime}(\theta)\right]^{2}+M^{\prime}(Q(\theta)) Q^{\prime \prime}(\theta)+\alpha W^{\prime}(Q(\theta)) Q^{\prime}(\theta)+\alpha \theta W^{\prime \prime}(Q(\theta))\left[Q^{\prime}(\theta)\right]^{2} \\
& +\alpha \theta W^{\prime}(Q(\theta)) Q^{\prime \prime}(\theta)-c_{s} Q^{\prime \prime}(\theta)=0 .
\end{aligned}
$$

The second order derivative for $\theta^{\prime}=\theta$ to be maximized should satisfy:

$$
\begin{aligned}
& M^{\prime \prime}(Q(\theta))\left[Q^{\prime}(\theta)\right]^{2}+M^{\prime}(Q(\theta)) Q^{\prime \prime}(\theta)+\alpha \theta W^{\prime \prime}(Q(\theta))\left[Q^{\prime}(\theta)\right]^{2} \\
& +\alpha \theta W^{\prime}(Q(\theta)) Q^{\prime \prime}(\theta)-c_{s} Q^{\prime \prime}(\theta) \leq 0 .
\end{aligned}
$$

The above analysis implies that the necessary condition is $\alpha W^{\prime}(Q(\theta)) Q^{\prime}(\theta) \geq 0$. It is because $W(Q(\theta))$ is assumed as an increasing function, that is, $W^{\prime}(Q(\theta))$ is greater than or equal zero. Therefore, the necessary condition becomes that $Q^{\prime}(\theta)$ is greater than or equal zero. That is, $Q(\theta)$ is an increasing function in $\theta$.

(ii) The second order derivative of the function in Equation (11) for $Q(\theta)$ is shown as:

$$
\frac{\partial^{2} G(Q(\theta))}{\partial Q^{2}(\theta)}=\left(r_{v}-p\right) \phi(Q(\theta))+\beta^{2}\left(w_{1}-w_{2}\right) h(\beta Q(\theta))+\alpha W^{\prime \prime}(Q(\theta))\left(\theta-\frac{1-F(\theta)}{f(\theta)}\right) .
$$

It is because the pdf function is greater than zero and the coefficients of the first two items in Equation (A.4) are negative values, thus, the first two terms of Equation (A.4) are non-positive. In addition, $W(Q(\theta))$ is an increasing concave function, thus, $W^{\prime \prime}(Q(\theta))$ is smaller than or equal zero. On the basis of the above analysis, the result 
of the second order condition for $G(Q(\theta))$ is non-positive if $\theta \geq \frac{1-F(\theta)}{f(\theta)}$. That is, $G(Q(\theta))$ is a concave function in $Q(\theta)$ if $\theta \geq \frac{1-F(\theta)}{f(\theta)}$.

Q.E.D.

PROOF OF PROPOSITION 2.

Taking the cross partial derivative of $G(Q(\theta))$ with respect to $Q(\theta)$ and $\theta$, we can get

$\frac{\partial^{2} G(Q(\theta))}{\partial Q(\theta) \partial \theta}=\alpha W^{\prime}(Q(\theta))\left[\frac{f(\theta)(1-F(\theta))+f^{2}(\theta)}{f^{2}(\theta)}+1\right]$

Therefore, under the condition of increasing failure rate, Equation (A.5) is greater than or equal zero. Because $W(Q(\theta))$ is an increasing function and other parts in Equation (A.5) is greater than zero.

Taking the cross partial derivative of $G(Q(\theta))$ with respect to $Q(\theta)$ and $w_{1}$, we can get $\frac{\partial^{2} G(Q(\theta))}{\partial Q(\theta) \partial w_{1}}=\beta H(\beta Q(\theta))>0$

Similarly, taking the cross partial derivative of $G(Q(\theta))$ with respect to $Q(\theta)$ and $w_{2}$, we can get

$$
\frac{\partial^{2} G(Q(\theta))}{\partial Q(\theta) \partial w_{2}}=-\beta H(\beta Q(\theta))<0
$$

Because $H(\beta Q(\theta))$ is an increasing function, thus, Equations (A.6) and (A.7) are greater and smaller than zero, respectively. Based on the theory on lattice and modularity (Topkis, 1998), $G(Q(\theta))$ is supermodular in $\left(Q(\theta), \theta, w_{1}\right)$ and submodular in $\left(Q(\theta), w_{2}\right)$ under the condition of increasing failure rate.

Q.E.D. 


\section{PROOF OF PROPOSITION 3.}

(i) Taking the first order derivative of $G(Q(\theta))$ with respect to $Q(\theta)$, then, we can obtain

$$
\begin{aligned}
\frac{\partial G(Q(\theta))}{\partial Q(\theta)}= & p-\beta w_{1}-c_{p}-c_{s}+\left(r_{v}-p\right) \Phi(Q(\theta))+\beta\left(w_{1}-w_{2}\right) H(\beta Q(\theta)) \\
& +\alpha W^{\prime}(Q(\theta))\left(\theta-\frac{1-F(\theta)}{f(\theta)}\right)
\end{aligned}
$$

Let

$$
\frac{\partial G(Q(\theta))}{\partial Q(\theta)}=0
$$

Then, the optimal $Q^{*}(\theta)$ can be derived from Equations (A.8) and (A.9). In addition, the optimal cash transfer can be obtained as follows:

Because

$$
\int_{\underline{\theta}}^{\theta} \alpha W\left(Q^{*}(\xi)\right) d \xi=r(\theta)=M\left(Q^{*}(\theta)\right)+\alpha \theta W\left(Q^{*}(\theta)\right)-c_{s} Q^{*}(\theta) .
$$

Thus,

$$
M\left(Q^{*}(\theta)\right)=\int_{\underline{\theta}}^{\theta} \alpha W\left(Q^{*}(\xi)\right) d \xi+c_{s} Q^{*}(\theta)-\alpha \theta W\left(Q^{*}(\theta)\right) .
$$

The optimal contract for the supplier is $\left(Q^{*}(\theta), M\left(Q^{*}(\theta)\right)\right)$.

(ii) Substituting Equation (A.11) into the payoff function of the supplier, we can obtain $\Pi_{s}=r(\theta)$. The result of the mixed partial differential in terms of $\theta$ and $Q(\theta)$ is $\alpha W^{\prime}(Q(\theta)) Q^{\prime}(\theta)$, which is greater than or equal zero, because both $W(Q(\theta))$ and $Q(\theta)$ are increasing functions. Thus, $\Pi_{s}$ is supermodular in $(\theta, Q(\theta))$.

Q.E.D.

\section{PROOF OF PROPOSITION 4.}

(i) In order to guarantee the $I C$ condition in Equation (16), we take the first order 
derivative for $\theta_{i}$, which aims at maximizing the payoff of the supplier $i$. Then,

$$
\left[m_{i}^{\prime}\left(q_{i}\left(\theta_{i}\right)\right)+\alpha_{i} \theta_{i} W_{i}^{\prime}\left(q_{i}\left(\theta_{i}\right)\right)-c_{s_{i}}\right] q_{i}^{\prime}\left(\theta_{i}\right)=0
$$

Thus, the second order derivative for $\theta_{i}$ is:

$$
\begin{aligned}
& m_{i}^{\prime \prime}\left(q_{i}\left(\theta_{i}\right)\right)\left(q_{i}^{\prime}\left(\theta_{i}\right)\right)^{2}+m_{i}^{\prime}\left(q_{i}\left(\theta_{i}\right)\right) q_{i}^{\prime \prime}\left(\theta_{i}\right)+\alpha_{i} W_{i}^{\prime}\left(q_{i}\left(\theta_{i}\right)\right) q_{i}^{\prime}\left(\theta_{i}\right)+\alpha_{i} \theta_{i} W_{i}^{\prime \prime}\left(q_{i}\left(\theta_{i}\right)\right)\left(q_{i}^{\prime}\left(\theta_{i}\right)\right)^{2} \\
& +\alpha_{i} \theta_{i} W_{i}^{\prime}\left(q_{i}\left(\theta_{i}\right)\right) q_{i}^{\prime \prime}\left(\theta_{i}\right)-c_{s_{i}} q_{i}^{\prime \prime}\left(\theta_{i}\right)=0 .
\end{aligned}
$$

The first order derivative for $\theta_{i}$ should be maximized by:

$$
\begin{aligned}
& m_{i}^{\prime \prime}\left(q_{i}\left(\theta_{i}\right)\right)\left(q_{i}^{\prime}\left(\theta_{i}\right)\right)^{2}+m_{i}^{\prime}\left(q_{i}\left(\theta_{i}\right)\right) q_{i}^{\prime \prime}\left(\theta_{i}\right)+\alpha_{i} \theta_{i} W_{i}^{\prime \prime}\left(q_{i}\left(\theta_{i}\right)\right)\left(q_{i}^{\prime}\left(\theta_{i}\right)\right)^{2} \\
& +\alpha_{i} \theta_{i} W_{i}^{\prime}\left(q_{i}\left(\theta_{i}\right)\right) q_{i}^{\prime \prime}\left(\theta_{i}\right)-c_{s_{i}} q_{i}^{\prime \prime}\left(\theta_{i}\right) \leq 0 .
\end{aligned}
$$

This implies that the necessary condition is $\alpha_{i} W_{i}^{\prime}\left(q_{i}\left(\theta_{i}\right)\right) q_{i}^{\prime}\left(\theta_{i}\right)$ greater than zero. Because $W_{i}\left(q_{i}\left(\theta_{i}\right)\right)$ is assumed as an increasing function, thus, the necessary condition becomes that $q_{i}^{\prime}\left(\theta_{i}\right)$ is greater than or equal zero. Thus, $q_{i}^{\prime}\left(\theta_{i}\right)$ is increasing in $\theta_{i}$.

(ii) Taking the second order derivative for the integral function in Equation (20) with respect to $Q_{i}\left(\theta_{1}, \mathrm{~K}, \theta_{n}\right)$, we can obtain the following result as shown in Equation (A.15):

$$
\begin{aligned}
\frac{\partial^{2} K\left(Q_{i}\left(\theta_{1}, \mathrm{~K}, \theta_{n}\right)\right)}{\partial Q_{i}^{2}\left(\theta_{1}, \mathrm{~K}, \theta_{n}\right)}= & \left(r_{v}-p\right) \phi\left(Q_{i}\left(\theta_{1}, \mathrm{~K}, \theta_{n}\right)\right)+\beta^{2}\left(w_{1}-w_{2}\right) h\left(Q_{i}\left(\theta_{1}, \mathrm{~K}, \theta_{n}\right)\right) \\
& +\alpha_{i} W_{i}^{\prime \prime}\left(Q_{i}\left(\theta_{1}, \mathrm{~K}, \theta_{n}\right)\right)\left(\theta_{i}-\frac{1-F_{i}\left(\theta_{i}\right)}{f_{i}\left(\theta_{i}\right)}\right)
\end{aligned}
$$

Because the pdf function is greater than zero and the coefficient of the first two items in Equation (A.15) are negative, in addition, $W\left(Q_{i}\left(\theta_{1}, \mathrm{~K}, \theta_{n}\right)\right)$ is an increasing concave function, therefore, the result of the second order condition of $K\left(Q_{i}\left(\theta_{1}, \mathrm{~K}, \theta_{n}\right)\right)$ is negative if $\theta_{i} \geq \frac{1-F_{i}\left(\theta_{i}\right)}{f_{i}\left(\theta_{i}\right)}$. That is, $K\left(Q_{i}\left(\theta_{1}, \mathrm{~K}, \theta_{n}\right)\right)$ is a concave function in $Q_{i}\left(\theta_{1}, \mathrm{~K}, \theta_{n}\right)$ if $\theta_{i} \geq \frac{1-F_{i}\left(\theta_{i}\right)}{f_{i}\left(\theta_{i}\right)}$. Q.E.D. 


\section{PROOF OF PROPOSITION 5.}

Taking the mixed partial differential in terms of $Q_{i}\left(\theta_{1}, \mathrm{~K}, \theta_{n}\right)$ and $\theta_{i}$ for Equation (20), we obtain the following result as shown in Equation (A.16):

$\frac{\partial^{2} K\left(Q_{i}\left(\theta_{1}, \mathrm{~K}, \theta_{n}\right)\right)}{\partial Q_{i}\left(\theta_{1}, \mathrm{~K}, \theta_{n}\right) \partial \theta_{i}}=\alpha_{i} W_{i}^{\prime}\left(Q_{i}\left(\theta_{1}, \mathrm{~K}, \theta_{n}\right)\right)\left(\frac{f_{i}^{2}\left(\theta_{i}\right)-f_{i}^{\prime}\left(\theta_{i}\right)\left(1-F_{i}\left(\theta_{i}\right)\right)}{f_{i}^{2}\left(\theta_{i}\right)}+1\right)$

Thus, under the condition of increasing failure rate, Equation (A.16) is no less than zero, it is because $W\left(Q_{i}\left(\theta_{1}, \mathrm{~K}, \theta_{n}\right)\right)$ is an increasing function. This result indicates that $K\left(Q_{i}\left(\theta_{1}, \mathrm{~K}, \theta_{n}\right)\right)$ is supermodular in $(\theta, Q(\theta))$ under the condition of increasing failure rate.

Q.E.D.

\section{PROOF OF PROPOSITION 6.}

(i) Following the results in Proposition $4, K\left(Q_{i}\left(\theta_{1}, \mathrm{~K}, \theta_{n}\right)\right)$ is a concave function in $Q_{i}\left(\theta_{1}, \mathrm{~K}, \theta_{n}\right)$. If $\theta_{1} \leq \theta_{2} \leq \mathrm{L} \leq \theta_{n}$, then, the optimal mechanism is $Q^{*}\left(\theta_{1}, \mathrm{~K}, \theta_{n}\right)=Q^{*}\left(\theta_{n}\right)$ and $Q^{*}\left(\theta_{j}\right)=0, j=1, \mathrm{~K}, n-1$. is the maximizer of the concave function $K\left(Q_{i}\left(\theta_{1}, \mathrm{~K}, \theta_{n}\right)\right)$. Therefore, the optimal payment can be characterized as follows:

$$
M_{i}\left(Q^{*}\left(\theta_{n}\right)\right)=\alpha_{i} W_{i}\left(Q^{*}\left(\theta_{n}\right)\right)\left(\frac{1-F_{i}\left(\theta_{n}\right)}{f_{i}\left(\theta_{n}\right)}-\theta_{n}\right)+c_{s_{i}} Q^{*}\left(\theta_{n}\right)
$$

Because

$$
\int_{\underline{\theta}}^{\theta} \alpha_{n} W_{n}\left(q_{n}^{*}(\xi)\right) d \xi=r_{n}\left(\theta_{n}\right)=m_{n}\left(q_{n}^{*}\left(\theta_{n}\right)\right)+\alpha_{n} \theta_{n} W_{n}\left(q_{n}^{*}\left(\theta_{n}\right)\right)-c_{s_{n}} q_{n}^{*}\left(\theta_{n}\right)
$$

Thus,

$$
M_{n}\left(q_{n}^{*}\left(\theta_{n}\right)\right)=\int_{\underline{\theta}}^{\theta} \alpha_{n} W_{n}\left(q_{n}^{*}(\xi)\right) d \xi+c_{s_{n}} q_{n}^{*}\left(\theta_{n}\right)-\alpha_{n} \theta_{n} W_{n}\left(q_{n}^{*}\left(\theta_{n}\right)\right)
$$

The optimal contract for the supplier is $\left(q_{n}^{*}\left(\theta_{n}\right), M_{n}\left(q_{n}^{*}\left(\theta_{n}\right)\right)\right)$.

(ii) Substituting Equation (A.19) into the payoff function of the supplier, then, the 
profit of supplier equals $r(\theta)$. The result of the mixed partial differential in terms of $\theta_{n}$ and $Q^{*}\left(\theta_{n}\right)$ is greater than or equal zero, because $W\left(Q_{i}\left(\theta_{1}, \mathrm{~K}, \theta_{n}\right)\right)$ is an increasing function.

Q.E.D.

\section{PROOF OF PROPOSITION 7.}

Based on the integrated function of the manufacturer,

$$
\begin{aligned}
G(Q(\theta))= & R(Q(\theta))+T(Q(\theta))-\alpha W(Q(\theta)) \frac{1-F(\theta)}{f(\theta)}+\alpha \theta W(Q(\theta))-c_{s} Q(\theta) \\
= & p \mathrm{E} \min (Q(\theta), D)+r_{v} \mathrm{E} \min (Q(\theta)-D)^{+}-c_{p} Q(\theta)+w_{1} \mathrm{E}(C-\beta Q(\theta))^{+} \\
& -w_{2} \mathrm{E}(\beta Q(\theta)-C)^{+}-\alpha W(Q(\theta)) \frac{1-F(\theta)}{f(\theta)}+\alpha \theta W(Q(\theta))-c_{s} Q(\theta)
\end{aligned}
$$

Thus, above equation can be rewritten as:

$$
\begin{aligned}
G(Q(\theta))= & \max \left\{R(Q(\theta))-M(Q(\theta))+w_{1} \mathrm{E}(C-\beta Q(\theta)),\right. \\
& \left.R(Q(\theta))-M(Q(\theta))-w_{2} \mathrm{E}(\beta Q(\theta)-C)^{+}\right\},
\end{aligned}
$$

where $M(Q(\theta))=\alpha W(Q(\theta)) \frac{1-F(\theta)}{f(\theta)}-\alpha \theta W(Q(\theta))+c_{s} Q(\theta)$.

Define

$$
\begin{aligned}
& U(Q(\theta))=\arg \max _{C}\left\{R(Q(\theta))-M(Q(\theta))+w_{1} \mathrm{E}(C-\beta Q(\theta))^{+}\right\} \\
& L(Q(\theta))=\arg \max _{C}\left\{R(Q(\theta))-M(Q(\theta))-w_{2} \mathrm{E}(\beta Q(\theta)-C)^{+}\right\}
\end{aligned}
$$

$\frac{\partial^{2} w_{1} \mathrm{E}(C-\beta Q(\theta))^{+}}{\partial Q(\theta) \partial \theta}=w_{1} \beta^{2} h(\beta Q(\theta)) Q^{\prime}(\theta)$

$$
\frac{\partial^{2} w_{2} \mathrm{E}(\beta Q(\theta)-C)^{+}}{\partial Q(\theta) \partial \theta}=w_{2} \beta^{2} h(\beta Q(\theta)) Q^{\prime}(\theta)
$$

Because both Equations (22) and (23) are greater than zero, thus, $w_{1} \mathrm{E}(C-\beta Q(\theta))^{+}$and $w_{2} \mathrm{E}(\beta Q(\theta)-C)^{+}$are supermodular in $(\theta, Q(\theta))$. In addition,

$\frac{\partial(R(Q(\theta))-M(Q(\theta)))}{\partial Q(\theta) \partial \theta}=\alpha W^{\prime}(Q(\theta)) \frac{f(\theta)(1-F(\theta))+f^{2}(\theta)}{f^{2}(\theta)}+\alpha W^{\prime}(Q(\theta))$ 
is greater than zero, thus, $R(Q(\theta))-M(Q(\theta))$ is supermodular in $(\theta, Q(\theta))$

Following the above analysis and the Theorem 2.6.4 (Topkis, 1998), both $T_{1}(Q(\theta), C)$ and $T_{2}(Q(\theta), C)$ are supermodular in $(\theta, Q(\theta))$. Therefore, following the above analysis and the Theorem 2.7.6 and Theorem 2.8.2 (Topkis, 1998), both $L(Q(\theta))$ and $U(Q(\theta))$ are increasing in $Q(\theta)$. Q.E.D..

\section{PROOF OF PROPOSITION 8.}

We focus on the first price auction only because the second price auction is straightforward. Assume player $j$ will bid lower than $p$ if and only if their order is less than $\delta^{-1}(p)$. Then, the probability for all players to bid less than $p$ is $\left(1-F\left(\delta^{-1}(p)\right)\right)^{n-1}$.

Thus, the supplier $i$ 's expected profit is $\Pi_{i}=\left(x-\mu\left(\theta_{i}\right) p\right) \operatorname{Pr}\left(p_{j}>\delta^{-1}(p)\right)$, $\delta(\cdot)$ is a Bayesian-Nash equilibrium only if $\Pi_{i}$ is maximized by $p=\delta(x)$. The first order condition for optimal $p$ should satisfy:

$-\delta^{\prime}(x)(F(x))^{n-1}+\left(x-\mu\left(\theta_{i}\right) \delta(x)\right)\left(F(x)^{n-1}\right)^{\prime}=0$.

The above equation can be written as:

$\left(\mu(\theta) \delta(x) F(x)^{n-1}\right)^{\prime}=x\left(F(x)^{n-1}\right)^{\prime}$

Let $\underline{x}$ be the smallest $x$ under which the bidder does not bid, then $\delta(x)=0$.

$\delta(x)=\frac{1}{F(x)^{n-1}} \int_{\underline{x}}^{x} z d F(z)^{n-1}=\frac{1}{\mu\left(\theta_{i}\right)} \mathrm{E}(P \mid P \leq p)$,

where $P=\max \left\{p_{j}\right\}, j=i$. Q.E.D.

\section{PROOF OF PROPOSITION 9.}

For a supplier with his bidding information $(\theta, M)$, if the supplier, with a certain performance $v$, wins the contract, the following mathematic programming model 
should be satisfied:

$$
\begin{aligned}
& \max _{\theta, M} \Pi_{s}=M(Q(\theta))+\alpha \theta W(Q(\theta))-c_{s} Q(\theta) \\
& \text { s.t. } \quad M(Q(\theta))+c_{m} Q(\theta)=v
\end{aligned}
$$

It is equivalent to maximizing $v-\left(c_{s}+c_{m}\right) Q(\theta)+\alpha \theta W(Q(\theta))$ with respect to decision variable $\theta$, the optimal value of $\theta$ can be expressed as:

$$
\theta^{*}=\arg \max _{\theta}\left\{v-\left(c_{s}+c_{m}\right) Q(\theta)+\alpha \theta W(Q(\theta))\right\}
$$

Assume supplier $i$ wins if and only if $v>\delta\left(v_{j}\right)$ or equivalently $\delta^{-1}(v)>v_{j}$ for all $j \neq i$, which occurs with probability $\operatorname{Pr}\left(\delta^{-1}(v)>v_{j}\right)$. Therefore, the expected profit of supplier $i$ is:

$$
\begin{aligned}
\Pi_{i} & =\left[v-\left(c_{s}+c_{m}\right) Q(\theta)+\alpha \theta W(Q(\theta))\right] \operatorname{Pr}\left(\delta^{-1}(v)>v_{j}\right) \\
& =\left[v-\left(c_{s}+c_{m}\right) Q(\theta)+\alpha \theta W(Q(\theta))\right]\left[F\left(\delta^{-1}(v)\right)\right]^{n-1}
\end{aligned}
$$

The first order derivative for the optimal $v$ should satisfy:

$$
F\left(\delta^{-1}(v)\right)^{n-1}+\left[v-\left(c_{s}+c_{m}\right) Q(\theta)+\alpha \theta W(Q(\theta))\right]\left[F\left(\delta^{-1}(v)\right)^{n-1}\right]^{\prime}=0 .
$$

Because $\theta=\delta^{-1}(v)$, then, $v=\delta(\theta)$, rearranging the above equation yields,

$$
[\delta(\theta)]^{\prime}=\left[\left(c_{s}+c_{m}\right) Q(\theta)-\alpha \theta W(Q(\theta))\right]\left[F\left(\delta^{-1}(v)\right)^{n-1}\right]^{\prime}
$$

which implies:

$$
\begin{aligned}
\delta(\theta) F\left(\delta^{-1}(v)\right)^{n-1} & =\int_{\underline{\theta}}^{\theta}\left\{\left[\left(c_{s}+c_{m}\right) Q(\xi)-\alpha \theta W(Q(\xi))\right]\left[F\left(\delta^{-1}(v)\right)^{n-1}\right]^{\prime}\right\} d \xi \\
\text { Let } H(v) & =\operatorname{Pr}\left\{\max \left\{v_{1}, v_{2}, \mathrm{~K}, v_{n-1}\right\} \leq v\right\}=F(v)^{n-1}, \quad Y=\max \left\{v_{1}, v_{2}, \mathrm{~K}, v_{n-1}\right\} .
\end{aligned}
$$

Then, $Y$ has its $\operatorname{cdf} H(\cdot)$ and $\operatorname{pdf} h(\cdot)$.

$$
\frac{\delta^{*}(\theta)}{H(\theta)} \int_{\underline{\theta}}^{\theta}\left[\left(c_{s}+c_{m}\right) Q(\xi)-\alpha \theta W(Q(\xi))\right] h(\xi) d \xi=\mathrm{E}\left[Z\left(\theta^{*}\right) \mid Y<v\right]
$$

where $Z\left(\theta^{*}\right)=\left(c_{s}+c_{m}\right) Q\left(\theta^{*}\right)-\alpha \theta W\left(Q\left(\theta^{*}\right)\right)$, therefore, $M^{*}(Q(\theta))=\delta^{*}(\theta)-c_{m} Q^{*}(\theta)$. Q.E.D. 